University of Nebraska - Lincoln

DigitalCommons@University of Nebraska - Lincoln

USGS Staff -- Published Research

US Geological Survey

2014

Pesticide Toxicity Index — A tool for assessing potential toxicity of pesticide mixtures to freshwater aquatic organisms

Lisa Nowell

USGS, lhnowell@usgs.gov

Julia Norman

USGS, jnorman@usgs.gov

Patrick Moran

USGS, pwmoran@usgs.gov

Jeffrey Martin

USGS, jdmartin@usgs.gov

Wesley Stone

USGS,wwstone@usgs.gov

Follow this and additional works at: http:/ / digitalcommons.unl.edu/usgsstaffpub

Nowell, Lisa; Norman, Julia; Moran, Patrick; Martin, Jeffrey; and Stone, Wesley, "Pesticide Toxicity Index—A tool for assessing potential toxicity of pesticide mixtures to freshwater aquatic organisms" (2014). USGS Staff -- Published Research. 818.

http:// digitalcommons.unl.edu/usgsstaffpub/818

This Article is brought to you for free and open access by the US Geological Survey at DigitalCommons@University of Nebraska - Lincoln. It has been accepted for inclusion in USGS Staff -- Published Research by an authorized administrator of DigitalCommons@University of Nebraska - Lincoln. 


\title{
Pesticide Toxicity Index -A tool for assessing potential toxicity of pesticide mixtures to freshwater aquatic organisms
}

\author{
Lisa H. Nowell ${ }^{\mathrm{a}, *}$, Julia E. Norman ${ }^{\mathrm{b}}$, Patrick W. Moran ${ }^{\mathrm{c}}$, Jeffrey D. Martin ${ }^{\mathrm{d}}$, Wesley W. Stone ${ }^{\mathrm{d}}$ \\ a U.S. Geological Survey (USGS), 6000 J Street, Placer Hall, Sacramento, CA 95819, USA \\ b USGS, 2130 SW 5th Avenue, Portland, OR 97201, USA \\ c USGS, 934 Broadway, Suite 300, Tacoma, WA 98402, USA \\ d USGS, 5957 Lakeside Boulevard, Indianapolis, IN 46278, USA
}

\section{H I G H L I G H T S}

- Pesticide Toxicity Index (PTI) is a tool to assess pesticide mixtures.

- PTI is an indicator of potential toxicity of pesticide mixtures to aquatic life.

- The PTI was updated and expanded to include 440 pesticides and 52 degradates.

- A new type of PTI provides a more sensitive indicator of potential toxicity.

- From published field data, daphnid mortality occurred above PTI values of 0.1 to 1 .

\section{A R T I C L E I N F O}

\section{Article history:}

Received 3 July 2013

Received in revised form 28 November 2013

Accepted 18 December 2013

Available online 22 January 2014

\section{Keywords:}

Pesticides

Mixtures

Aquatic toxicity

Water quality

Indicators

\begin{abstract}
A B S T R A C T
Pesticide mixtures are common in streams with agricultural or urban influence in the watershed. The Pesticide Toxicity Index (PTI) is a screening tool to assess potential aquatic toxicity of complex pesticide mixtures by combining measures of pesticide exposure and acute toxicity in an additive toxic-unit model. The PTI is determined separately for fish, cladocerans, and benthic invertebrates. This study expands the number of pesticides and degradates included in previous editions of the PTI from 124 to 492 pesticides and degradates, and includes two types of PTI for use in different applications, depending on study objectives. The Median-PTI was calculated from median toxicity values for individual pesticides, so is robust to outliers and is appropriate for comparing relative potential toxicity among samples, sites, or pesticides. The Sensitive-PTI uses the 5th percentile of available toxicity values, so is a more sensitive screening-level indicator of potential toxicity. PTI predictions of toxicity in environmental samples were tested using data aggregated from published field studies that measured pesticide concentrations and toxicity to Ceriodaphnia dubia in ambient stream water. C. dubia survival was reduced to $\leq 50 \%$ of controls in $44 \%$ of samples with Median-PTI values of $0.1-1$, and to $0 \%$ in $96 \%$ of samples with Median-PTI values $>1$. The PTI is a relative, but quantitative, indicator of potential toxicity that can be used to evaluate relationships between pesticide exposure and biological condition.
\end{abstract}

Published by Elsevier B.V.
Abbreviations: CA, concentration addition; CCWQP, Central Coast Water Quality Preservation; CWA, Clean Water Act; DPR, California Department of Pesticide Regulation; EC50, 50 percent effective concentration; ECOTOX, ECOTOXicology database; $\mathrm{HCp}$, pth percentile hazardous concentration; $\mathrm{K}_{\mathrm{ow}}$, octanol/water partition coefficient; LC50, 50 percent lethal concentration; maxTU, the maximum TU of any single component in a mixture; MOA, mode of action; msPAF, multi-substance Potentially Affected Fraction; MTC, median toxicity concentration; NAWQA, National Water-Quality Assessment Program; NOEC, no-observed-effect concentration; O/E, observed-to-expected ratio; OPP, Office of Pesticide Programs; PPDB, Pesticide Properties Database; PTI, Pesticide Toxicity Index; RA, response addition; SMAV, species mean acute value; SSD, species sensitivity distribution; STC, sensitive toxicity concentration; TC, toxicity concentration; TU, toxic unit; USEPA, U.S. Environmental Protection Agency; USGS, U.S. Geological Survey.

* Corresponding author. Tel.: + 1916278 3096; fax: + 19162783070.

E-mail addresses: lhnowell@usgs.gov (L.H. Nowell), jnorman@usgs.gov (J.E. Norman), pwmoran@usgs.gov (P.W. Moran), jdmartin@usgs.gov (J.D. Martin),wwstone@usgs.gov (W.W. Stone).

\section{Introduction}

A major challenge when assessing the water quality of streams is to link contaminant data to effects on aquatic biota, particularly for pesticides, which tend to occur in streams as complex mixtures with strong seasonal and geographic patterns. In data collected during 1992-2001 by the U.S. Geological Survey's (USGS) National Water Quality Assessment (NAWQA) Program, U.S. streams with substantial agricultural and(or) urban land within their watersheds had detections of 2 or more pesticides or degradates in water more than $90 \%$ of the time, 5 or more about $70 \%$ of the time, and 10 or more about $20 \%$ of the time (Gilliom et al., 2006). The most common way of directly assessing potential effects of pesticides is through the use of standardized laboratory toxicity tests that expose a single species to a single pesticide over a 
range of concentrations for a specified period of time. Comparison of such toxicity test results among pesticides (or for a pesticide among test organisms) indicates the relative toxicity of these pesticides (or the relative toxicity of that pesticide to these test organisms) under standardized test conditions, but doesn't address many factors that are important in extrapolating to field conditions. Such factors include the dose-response relationship; mode(s) of action; endpoints selected; environmental factors (such as organic carbon, $\mathrm{pH}$, and temperature); and potential for additive or interactive effects of contaminant mixtures. This paper addresses one of these factors-exposure to pesticide mixtures-and presents the Pesticide Toxicity Index (PTI) as a robust and readily applicable screening tool for interpreting the biological significance of concentration data for pesticide mixtures in hydrologic systems.

Procedures developed in previous studies to predict or evaluate the effects of pesticide mixtures using standardized single-species toxicity test data commonly share two steps: (1) environmental concentrations of individual pesticides are divided by compound-specific measures of toxicity or effect, and then (2) a model is applied to combine the contributions of individual pesticides in the mixture.

First, individual chemical concentrations have long been scaled to some measure of toxicity or effect (Bliss, 1939) as part of a toxic unit (TU) approach (Sprague and Ramsay, 1965). Studies have differed in key details, however, such as type(s) of toxicity measures used, taxonomic groups included, procedures for selecting one toxicity value to represent a compound when multiple values were available, and procedures for handling pesticides with no toxicity data available (examples cited below).

- TUs for pesticides have been calculated using acute 50-percent lethal or effective concentrations (LC50 or EC50, respectively) (Battaglin and Fairchild, 2002; Guy et al., 2011; Munn and Gilliom, 2001; Munn et al., 2006; Schäfer et al., 2011a, 2011b; Stenström, 2013), chronic noobserved-effect concentrations (NOECs) or LC50/EC50s multiplied by a safety factor to represent chronic effects (Anderson, 2008), water-quality standards (Stenström, 2013), and hazardous concentrations (HC) derived from species sensitivity distributions (SSD) (Guy et al., 2011; Maltby et al., 2005, 2009; Sala et al., 2012; Schäfer et al., 2013; Whiteside et al., 2008). A SSD entails fitting a statistical distribution to toxicity data for certain broad taxonomic groups, and SSDs can be constructed from acute LC50/EC50 values (Schäfer et al., 2013; Whiteside et al., 2008), chronic NOEC values, or any other selected toxicity criterion (Posthuma and de Zwart, 2006). From the concentration-effect relationship, a specific HC (HCp) can be derived that corresponds to effects on $\mathrm{p} \%$ of species.

- TUs have been calculated for a single taxon such as Daphnia magna (Guy et al., 2011; Liess and von der Ohe, 2005; Schäfer et al., 2011a, 2011b; Stenström, 2013), the most sensitive taxon (i.e., the taxon with the lowest LC50) (Schäfer et al., 2013), or taxonomic groups such as cladocerans (Munn et al., 2006). Similarly, SSDs may represent a fairly narrow taxonomic group such as arthropod invertebrates (Maltby et al., 2005, 2009; Sala et al., 2012), crustaceans (Whiteside et al., 2008), or broader groups such as freshwater invertebrates (Schäfer et al., 2013), aquatic animals (Etterson, 2011), or a combination of aquatic animals, aquatic macrophytes and algae (Maltby et al., 2009).

- When multiple toxicity values are available for a given pesticide, different studies selected the minimum value (Anderson, 2008), the median (Munn et al., 2006), the geometric mean (MacDonald et al., 2000; Sala et al., 2012), or the mean value (Battaglin and Fairchild, 2002). The U.S. Environmental Protection Agency's (USEPA) Office of Pesticide Programs (OPP) uses minimum values for ecological risk assessment and for calculating OPP aquatic-life benchmarks (http://www. epa.gov/oppefed1/ecorisk_ders/aquatic_life_benchmark.htm). The geometric mean is used by USEPA's Office of Water for computing Species Mean Acute Values (SMAV) in deriving USEPA water-quality criteria for protection of aquatic organisms (Stephan et al., 1985). The median and geometric mean values are more robust to outliers, which is important because toxicity values for a given compound may vary over several orders of magnitude, reflecting variability both among species and among tests for the same species.

- For pesticides with little or no experimental toxicity test data available, previous studies either omitted such pesticides from the index (Anderson, 2008; Munn et al., 2006) or estimated their toxicity values from structurally similar compounds (Battaglin and Fairchild, 2002; Schäfer et al., 2011b), compounds with the same MOA (Sala et al., 2012), or the octanol/water partition coefficient $\left(\mathrm{K}_{\mathrm{ow}}\right)$ using quantitativestructure-activity relationships (Schäfer et al., 2011a, 2011b).

For the present study, as will be described, we selected the median and 5th percentile of all applicable acute toxicity values (LC50/EC50s) for a given compound and taxonomic group to compute TUs, in order to maximize the number of pesticides included in the index, while using a robust and readily transparent approach based on experimental toxicity data.

In the second step, after concentrations have been scaled to toxicity, a model is applied to assess the contribution of individual components of the mixture to overall toxicity. A number of approaches have been used in previous studies:

- The most common model for combining TUs of pesticide components of a mixture is concentration addition (CA), which entails summing TUs for individual compounds in a mixture (Bliss, 1939; Sprague and Ramsay, 1965). CA assumes that components of the mixture behave as concentrations or dilutions of one another, differing only in their potencies, and do not interact. In theory, CA applies to compounds with a similar mode of action (MOA) and dose-response curves.

- The response addition (RA) model (also called independent action) assumes that compounds in the mixture act independently, so the combined effect is calculated according to the probability of non-excluding processes (Bliss, 1939; de Zwart and Posthuma, 2005).

- In the maximum TU (maxTU) approach, only the most toxic component of a mixture is considered, and potential contributions from other compounds in the mixture are assumed to be negligible (Liess and von der Ohe, 2005; Schäfer et al., 2011a, 2011b, 2012).

- For complex pesticide mixtures, de Zwart and Posthuma (2005) combined CA (for compounds with the same MOA) and RA (for compounds with different MOAs) in a two-stage model called the multi-substance Potentially Affected Fraction (msPAF) model. The msPAF model has been applied to assess assemblage metrics for fish and invertebrates (Posthuma and de Zwart, 2006, 2012; Schäfer et al., 2013).

For the present study, as will be described, we used the CA model. Studies of mixtures have shown that for compounds with a similar MOA, the CA model generally provides accurate predictions and the RA model may underestimate effects; but for compounds with different MOAs, the RA model provides more accurate predictions and the CA model may overestimate toxicity (Backhaus and Faust, 2012; Belden et al., 2007; Faust et al., 2000, 2003; Junghans et al., 2006). However, several studies of pesticide mixtures have shown that toxicity predicted using the CA model was within a factor of 2 or 3 of the observed toxicity, regardless of the MOA of the components (Belden et al., 2007; Faust et al., 2003; Warne, 2003). Moreover, application of the RA model, or a two-stage combination of CA and RA models, requires additional data on the MOA for each compound (which may be unknown or may vary for organisms in different trophic levels) and on dose-response curves for compounds with dissimilar MOAs (which are usually required to assess the effect that each compound would have if it were applied singly at the concentration at which it is present in the mixture) (Backhaus and Faust, 2012). For field samples, which may contain a large number of pesticides with similar, dissimilar, and unknown MOAs, CA appears to 
be a slightly conservative, but broadly applicable model with a relatively small likelihood of underestimating effects (Backhaus and Faust, 2012; Belden et al., 2007).

A limitation of the CA and RA models is that they do not account for potential interactive effects among pesticides in a mixture. In general, interactive effects have been reported to occur in 10-30\% of studies (Deneer, 2000; Faust et al., 1994; Warne and Hawker, 1995), were fairly evenly divided between synergism and antagonism, and typically did not deviate much from additivity (Warne and Hawker, 1995). Most studies of pesticide interaction have evaluated only limited endpoints, such as acute mortality or immobilization for animals and simple short-term growth measures for plants (Belden et al., 2007). The incidence of interactive effects may depend on the endpoint measured and test duration (Cedergreen and Streibig, 2005), on the test chemicals (Deneer, 2000; Lydy et al., 2004), and possibly on test species (Cedergreen et al., 2008).

Schäfer et al. (2011a) preferred the maxTU over the summed TUs (CA model) because the sum of TUs exhibited a stronger dependency on the number of compounds measured and could overestimate the toxicity of compounds with a dissimilar mode of action. Because the maxTU approach considers only the component with the highest toxic unit value, it does not require additional data on MOA or dose-response. The observation that RA models may underestimate toxicity for mixtures of similarly acting compounds (Backhaus and Faust, 2012) suggests that the same may be the case for the maxTU approach, which includes only the most toxic component of a mixture. However, the sum of TUs and the maxTU were highly correlated with one another, and both had a similar relationship to macroinvertebrate abundance in streams in Australia and Europe (Schäfer et al., 2011a).

The PTI approach presented in this paper is a variation of a riskbased scoring system described by Kimerle et al. (1997). The PTI was first developed by Munn and Gilliom (2001) for use with data on pesticides in stream water collected as part of the NAWQA Program, and was updated in 2006 (Munn et al., 2006). The PTI is a TU procedure that follows the CA model. This approach was selected because CA is a slightly conservative (protective), broadly applicable model that requires only standard toxicity data for individual pesticides, and is suitable as a robust screening tool for application to complex environmental mixtures of pesticides with similar, dissimilar, or unknown MOAs. Thus, the PTI approach allows us to maximize the number of pesticides included in the mixtures index, using only experimental data. As originally developed, PTI values are derived separately for fish, cladocerans, and benthic invertebrates by using the median of acute LC50s and EC50s for appropriate test species in standardized tests. Because only experimental data are used, any pesticides without standardized test data available for organisms in a given taxonomic group are omitted from the PTI calculations for that taxonomic group. The PTI may under-represent the relative acute toxicity of pesticides in a water sample because PTI calculations are limited to pesticides that (i) are measured and (ii) have toxicity data available. Because it is based on median toxicity values, the original PTI is relatively robust to outliers, but it would not necessarily be indicative of possible effects on all species in all life stages that may be exposed in hydrologic systems.

The PTI can be applied to pesticide mixtures detected in ambient water samples from hydrologic systems and used to interpret data in a number of ways. PTI values for individual samples can be used to rank sites or samples according to their expected relative toxicity due to pesticides, to assess changes in potential toxicity over time at a single site, or to predict which of the pesticides detected may be the greatest contributor to potential toxicity for a site or sample. PTI values for samples, seasons, or sites have been used as explanatory variables in multivariate analyses designed to determine which environmental variables best explain spatial patterns in the structure of a biological community (Fuhrer et al., 2004; Waite et al., 2006). As described further in Section 3.2, the PTI originally was designed to be an indicator of relative toxicity, and was not necessarily appropriate as a sensitive tool for predicting whether pesticide mixtures in water samples are likely to be toxic to aquatic organisms.

The present paper updates and modifies the PTI, which initially was developed for 75 pesticides (Munn and Gilliom, 2001) and later expanded to 124 pesticides analyzed by the NAWQA program (Munn et al., 2006). The objectives of this paper are to (1) expand the target list of pesticides to all pesticides used in agriculture in the U.S. from 1992 to 2011; (2) update and expand experimental toxicity data using additional data sources and acceptable endpoints; (3) investigate the possibility of basing the PTI on more sensitive toxicity values; and (4) apply the PTI method to past field studies to test how well the PTI predicted toxicity in these studies and to illustrate its application to interpret water-quality data.

\section{Methods}

The PTI methodology used in the present study follows that of previous editions (Munn and Gilliom, 2001; Munn et al., 2006), except for some important modifications. The target analyte list was expanded to include nearly 500 pesticides from an agricultural use database for the U.S. (described below). Toxicity data sources and endpoints were expanded to increase the number of pesticides with experimental toxicity data, including the use of the LC50 as well as the EC50 (immobilization) endpoints for cladocerans; use of non-standard data for those pesticides that have no standard test data available; and addition of toxicity data from OPP risk assessment documents and the Pesticide Properties Database (PPDB). Finally, the PTI from previous editions (here called "Median-PTI") was supplemented with a second type of PTI ("Sensitive-PTI") that was calculated using more sensitive toxicity concentrations. These changes are described further in Sections 2.1-2.3.

\subsection{Toxicity data sources}

A master list of 484 pesticides was compiled from agricultural pesticide use lists for 1992 to 2011 (GfK Kynetec, 2009; personal communication, Melissa Sims, Senior Business Development Manager Americas, GfK Kynetec, June 1, 2012), and was composed of 197 herbicides; 135 insecticides, acaricides and nematicides; 105 fungicides; 9 fumigants; 4 adjuvants and synergists; and 34 other miscellaneous pesticides. In addition, a master list of 104 pesticide degradates included high priority (Tier 1) degradates identified during a pesticide prioritization effort by the U.S. Geological Survey (Norman et al., 2012).

For these 484 pesticides and 104 degradates, the following sources were searched for experimental toxicity test data: USEPA's ECOTOXicology (ECOTOX) database (U.S. Environmental Protection Agency, 2012a); USEPA registration and risk assessment documents cited in support of the OPP aquatic-life benchmarks (U.S. Environmental Protection Agency, 2012b); and the PPDB (University of Hertfordshire, 2013). The ECOTOX database was queried for toxicity data for pesticides on July 5, 2012 and degradates on February 20, 2013. Toxicity data from OPP documents and the PPDB were compiled during September-October 2012 for pesticides and May 2013 for degradates. Details about each of these data sources are provided in Appendix A of the online supplementary information that accompanies this paper. Toxicity test data were selected as follows, in order of priority:

- Standardized toxicity test data from the ECOTOX database (U.S. Environmental Protection Agency, 2012a). Standardized data are defined as meeting the screening criteria in Table 1;

- Toxicity test data from core or supplemental studies underlying OPP aquatic-life benchmarks or summarized in registration documents cited by USEPA (2012b);

- Non-standard toxicity test data from the ECOTOX database-i.e., tests that did not meet the screening criteria in Table 1 , or that had 
Table 1

Standard criteria for toxicity test duration, endpoint, and measured effect, by taxonomic group. [EC50, 50 percent effective concentration; LC50, 50 percent lethal concentration].

\begin{tabular}{lll}
\hline Taxonomic group: & Fish or benthic invertebrates & Cladocerans \\
\hline Duration (hours) & 96 & 48 \\
Endpoint & LC50 & LC50 or EC50 \\
Effect & Mortality & Mortality or immobilization \\
Value & Discrete & Discrete \\
\hline
\end{tabular}

unbounded toxicity values (i.e., reported as "greater than" or "less than" a specified concentration, such as $>100 \mu \mathrm{g} / \mathrm{L}$ );

- Toxicity values compiled from the PPDB (University of Hertfordshire, 2013).

Bioassay data used in this paper are for fish and invertebrates only. When querying the ECOTOX database, specific species were not queried by name; the species list of aquatic animals included crustaceans, fish, insects/spiders, other invertebrates, and molluscs. Most species in the data query output are uniquely found in freshwater environments; however, a limited number of species spend part of their life cycle in the freshwater environment (e.g., salmon), or are known to inhabit marine or estuarine habitats but were tested under freshwater conditions. Bioassay data records were removed for sponges, microcrustaceans such as rotifers and ostracods, worms such as turbellarians and oligochaetes, protozoans, and ciliates, which were not retained with the invertebrates. In addition, bioassays were limited to laboratory tests conducted in freshwater, which the ECOTOX database defines as having salinity of 4 parts per thousand or below (U.S. Environmental Protection Agency, 2011). Subsequently, ECOTOX test data were subdivided by taxonomic group, and classified as standard (Table 1) or non-standard as described in Section 2.2.

For pesticides without standardized test data in ECOTOX, but that have acute OPP aquatic-life benchmarks for fish and(or) invertebrates, toxicity values associated with those benchmark values (U.S. Environmental Protection Agency, 2012b) were compiled from the cited source document. Toxicity values obtained from OPP documents were the cited LC50 or EC50 values, and were not equivalent to the acute OPP benchmarks themselves, which include an additional safety factor of 2. Some OPP benchmark values are unbounded because the EC50 or LC50 was greater than the highest concentration tested or less than the lowest concentration tested. Unbounded LC50 or EC50 values were considered non-standard data (Table 1; Section 2.2).

Aquatic toxicity values for pesticide compounds that did not have data available from ECOTOX or OPP documents were obtained from the PPDB (University of Hertfordshire, 2013), when available. Data included experimental 96-h LC50 values for fish (usually rainbow trout), 48-h EC50 values for aquatic invertebrates (usually D. magna), and 96h LC50 values for sediment dwelling organisms (usually the midge, Chironomus riparius). In the present study, toxicity values from the PPDB were limited to those with (1) standard test durations and (2) confidence scores of 5 (verified with regulatory purpose), 4 (verified), or 3 (unverified but known source). For LC50 values, the effect (mortality) can be inferred, but for cladoceran EC50 values, the effect was not reported in the PPDB but was accepted for the present paper as likely referring to immobilization, and therefore standard. Toxicity values from the PPDB were considered standard if the test duration, endpoint, and species were appropriate and the values were discrete; if the reported toxicity value was unbounded, the endpoint was non-standard, or the species was not reported, then the toxicity value was considered to be non-standard.

\subsection{Data screening process}

The criteria for standardized test data in Table 1 are identical to those used in previous editions of the PTI, with one exception-for cladocerans, the inclusion of the LC50 values is new, as only EC50s based on immobilization were used previously (Munn and Gilliom, 2001; Munn et al., 2006). Both endpoints are widely used and it is difficult to ascertain organism mortality with certainty without examining the organism under a dissecting microscope for a heartbeat (Jonczyk and Gilron, 2005). Standardized methods are available for both immobilization (Commission of the European Communities, 1992; Organization for Economic Cooperation and Development, 2004; U.S. Environmental Protection Agency, 1996) and mortality (U.S. Environmental Protection Agency, 2002). Inclusion of LC50 values for cladocerans may increase the median toxicity value for cladocerans to some degree; however, this represents only one of many sources of uncertainty in experimental toxicity test data (Section 3.4). The added uncertainty from combining LC50 with EC50 values is countered by the increase in the number of data records: Of the 2064 toxicity values for cladocerans in the present study, 739 (36\%) were LC50 values, allowing determination of toxicity concentrations for an additional 24 pesticides for which EC50 values for immobilization were not available. The rationale for including LC50 values for cladocerans is discussed further in Appendix $A$ of the supplementary information.

For pesticide compounds that did not have standardized test data (Table 1) available, non-standard test data were selected using the screening procedure below. Non-standard toxicity values were characterized by the direction of bias where possible.

- Concentration: If non-standard tests with discrete values were available, then only these tests were used, and any tests with results reported as unbounded or as concentration ranges were omitted. If no available studies reported discrete values, then toxicity values that were unbounded or ranges were retained, subject to further screening below. A toxicity value expressed as a greater-than concentration (e.g., >100 $\mu \mathrm{g} / \mathrm{L}$ ) was considered to overestimate toxicity, and a result expressed as a less-than concentration to underestimate toxicity. For test results expressed as a concentration range (e.g., $>100 \mu \mathrm{g} / \mathrm{L}$ but $<1000 \mu \mathrm{g} / \mathrm{L}$ ), the unbounded low end of the range was retained (this only applied to one test).

- Effect: For fish studies, the only acceptable endpoint was mortality. For cladocerans and benthic invertebrates, if one or more studies had immobilization or mortality measured, all tests with other effects measured (such as population growth or hatching success) were omitted; if all invertebrate tests had non-standard effects measured, then these tests were retained, subject to screening for duration. Typically the direction of bias in such cases was rated as unknown.

- Duration: If all available studies had non-standard exposure periods, then the tests with the duration closest to the standard duration were selected; if test durations were both shorter and longer (to a comparable degree) than the standard test duration, then the longer period was selected to be more protective. For example, if the standard duration is 4 days, and there were data for $1,2,5$, and 21 days, then the 5-day study was selected. In occasional cases where the longer exposure periods did not have the lowest (most sensitive) toxicity values, then all discrete toxicity values associated with all acute test durations were included. A study with long exposure duration was considered to overestimate toxicity, and a study with short exposure duration to underestimate toxicity.

\subsection{Development of the Pesticide Toxicity Index}

The PTI is determined separately for three taxonomic groups: fish, cladocerans, and benthic invertebrates. Cladocerans are treated separately from benthic invertebrates because of differences in physiology, habitat and functional group. In addition, their long history of use in toxicity testing has resulted in a large cladoceran dataset with a relatively small number of genera. 
The $\mathrm{PTI}_{t}$ is the sum of toxicity quotients for each pesticide compound (i) measured in ambient water from a hydrologic system, for each taxonomic group $(t)$ :

$\mathrm{PTI}_{t}=\sum_{i=1}^{\mathrm{n}}\left(\mathrm{E}_{i} / \mathrm{TC}_{i, t}\right)$

where $\mathrm{E}_{i}$ is the concentration of pesticide $i, \mathrm{n}$ is the number of detected pesticides in an environmental sample, and $\mathrm{TC}_{i t}$ is the toxicity concentration for the pesticide $i$ for the taxonomic group $t$. E and TC are expressed in the same units.

The PTI of Munn and Gilliom (2001) and Munn et al. (2006) was computed from Eq. (1) using the median of toxicity values available for a given pesticide. The median was selected because, for pesticides, there is a large difference in sensitivities of different taxonomic groups (Maltby et al., 2005, 2009; Sala et al., 2012; van den Brink et al., 2006). Even under standardized test conditions within a taxonomic group, there is considerable variability in toxicity values for many pesticides. In data compiled for the present study, the distribution of standard toxicity values for a given pesticide within a taxonomic group spanned up to 3-4 orders of magnitude for pesticides with 20 or more toxicity test values available, and extreme values-defined as more than three orders of magnitude from the median-occurred for 17 to $41 \%$ of these pesticides, depending on the taxonomic group. Factors that may contribute to variability include differences between test organisms, test conditions, and pesticide test material (see Section 3.4).

On the other hand, the use of median toxicity values in the PTI means that the concentration selected for a given pesticide may not be representative of some sensitive species or life stages. For certain applications of the PTI, a more sensitive indicator of toxicity may be preferable. Therefore, for the present study, the PTI method was modified to include two types of PTI values for a given taxonomic group, which are computed by using two different types of TC values in Eq. (1):

- The Median-PTI is calculated from Eq. (1) using the median toxicity concentration (MTC), which is defined as the median of the toxicity values available for each compound towards the taxonomic group. The Median-PTI is equivalent to the original PTI of Munn et al. (2006), except for some modifications to the kinds of toxicity data that are acceptable (Sections 2.1 and 2.2).

- The Sensitive-PTI is calculated from Eq. (1) using the sensitive toxicity concentration (STC). The STC is either the 5th percentile or (if fewer than 13 values were available) the minimum toxicity value for each compound towards the taxonomic group (Section 2.4).

MTC values are robust to outliers and provide a more consistent representation of relative toxicity values among pesticides, whereas STC values provide a more sensitive indication of potential toxicity to aquatic organisms. Because extreme values were fairly prevalent in the toxicity test dataset, care was taken to minimize the likelihood of selecting an outlier as the STC (Section 2.4 and Supplemental Appendix A).

\subsection{Determination of STC values}

The 5th percentile of the available toxicity values was selected as the STC because it is a sensitive indicator of relative toxicity, yet it is more robust to outliers than the minimum value is. Species that have a greater number of toxicity tests available will have more influence on the STC than other species. The most frequently tested species tended to be among the more sensitive species within this dataset (Supplemental Appendix A); therefore, STCs tended to be biased low (i.e., to overestimate toxicity), which was considered acceptable because the objective of the STC was to establish a sensitive indicator of potential toxicity to aquatic life.
The toxicity value percentiles were determined for each pesticide compound within a taxonomic group using the Cunnane (1978) plotting position of 0.4, as recommended by Helsel and Hirsch (1992), and linear extrapolation. The quantile.default function in Spotfire $S+8.1$ (TIBCO Software Inc., 2008) was used to perform the computations.

For pesticide compounds with 20 or more toxicity values available, the 5th percentile was used as the STC. For pesticide compounds with 13 to 19 toxicity values available, the STC was the 5th percentile as determined using linear extrapolation, with the two lowest ranked toxicity values used to extrapolate near or below the minimum value. One consequence of this extrapolation method is that if the lowest two toxicity values were a tie, then the 5 th percentile value was equal to the minimum. For pesticide compounds with 12 or fewer toxicity values, the minimum value was used as the STC in lieu of the 5th percentile. Monte Carlo simulations (detail in Supplemental Appendix A) showed that, for pesticides with 12 or fewer toxicity values available, the probability was less than $50 \%$ that the minimum toxicity value was a statistical outlier, defined as within the lowest 5th percentile of a hypothetical large population of toxicity values.

As described in Supplemental Appendix A, an alternative approach was evaluated in which toxicity tests were first aggregated by species and SMAVs were computed as the geometric mean of all tests for a given species and compound; the STC then was determined to be either the lowest SMAV or (for compounds with more than 12 species) the 5 th percentile of the SMAVs. The resulting species-weighted STCs were not only highly correlated with the unweighted STCs, although species weighting raised STC values for many pesticides, but also (for those pesticides whose lowest SMAV was based on a single test) increased the likelihood of selecting a possible low outlier as the STC (see Supplemental Appendix A.3 for further discussion and examples). For compounds with multiple tests available for only a single species, selecting the lowest SMAV as the STC resulted in a value that was similar to (or even greater than) the MTC, rather than a more conservative, sensitive value. In theory, it would be preferable to weight species equally when determining the STC; however, in practice this was problematic because of the unevenness and scarcity of the toxicity test dataset (Supplemental Appendix A.3). Although the unweighted STC is more influenced by results for some species than for others, a species-weighted STC would be more influenced by results of some individual tests than of others.

\subsection{Application of the Pesticide Toxicity Index to interpret water-quality data}

To test the PTI model and to illustrate its application to water-quality data, published studies were compiled that reported concurrent data on pesticide concentrations and aquatic toxicity. These studies reported raw data for both (1) concentrations of a substantial number of pesticides in ambient stream water and (2) organism survival in toxicity tests conducted in the laboratory with undiluted ambient water. Studies included a series of reports and memoranda on pesticides and toxicity in California streams published by the California Department of Pesticide Regulation (DPR) (Ensminger et al., 2009; Ganapathy, 1999a, b; Gill, 2002; Jones, 2000; Kim et al., 1999a, b; Nordmark, 1999, 2000; Walters et al., 2000a, 2000b, 2000c, 2000d, 2000e, 2000f, 2000g, 2000h, 2000i, 2000j, 2000k, 2000l, 2000m, 2001a, 2001b, 2001c, 2001d, 2001e, 2001f, 2001g, 2001h, 2001i, 2001j) and the Central Coast Water Quality Preservation (CCWQP) $(2008,2009)$. Some independent studies also provided suitable data (Kuivila and Foe, 1995; Phillips et al., 2012).

These studies measured acute toxicity to Ceriodaphnia dubia in 4 to 8-day laboratory exposures to undiluted ambient stream water, so results were compared to the PTI for cladocerans (Section 3.3.1). When data were aggregated from these studies, the total number of individual samples was 479 (Table 3). Samples from CCWQP $(2008,2009)$ and Kuivila and Foe (1995) were exposed for 6-8 days (total $n=174$ samples), whereas the remaining samples in the aggregated dataset were 
exposed for 4 days ( $\mathrm{n}=305$ samples). Each study analyzed between 8 and 27 parent pesticides, and collected water samples between 1993 and 2009 (Table 3). All aggregated samples were from California and most studies focused on organophosphate insecticides, which were responsible for placement of some California streams on the Clean Water Act (CWA) §303(d) list (Central Coast Water Quality Preservation Inc., 2008, 2009; Ensminger et al., 2009).

The results from one study in Table 3 that analyzed multiple classes of pesticides-a study of dormant spray pesticides by the California DPR (Gill, 2002; Nordmark, 1999, 2000)-are described in more detail to illustrate application of the PTI to interpret water-quality data (Section 3.3.2). For the purposes of discussion, the term "toxic" is defined in this paper as reduction of $C$. dubia survival to $\leq 50 \%$ of that in control samples. Although not statistically based, the $50 \%$ value in this definition corresponds to the EC50/LC50 values from which PTI values are calculated. Spearman rank correlations and least-square regressions were performed using DataDesk 6.3.1.

Invertebrate community condition in streams across the U.S. was assessed as part of the USGS NAWQA Program during 1993-2005 (Bryant and Carlisle, 2012; Carlisle and Meador, 2007; Carlisle et al., 2013; Yuan et al., 2009). Invertebrate communities were characterized by quantifying the deviation of a site's measured macroinvertebrate composition from the expected composition, expressed as the ratio of observed/expected $(\mathrm{O} / \mathrm{E})$ taxa. The $\mathrm{O} / \mathrm{E}$ index provides a way to compare across sites because it is standardized by each site's potential for species composition and richness. Expected invertebrate assemblage compositions (E) for each site were the sum of predicted probabilities of capturing common species at a given site, derived from predictive models developed from regional reference sites (Carlisle and Hawkins, 2008; Carlisle and Meador, 2007; Yuan et al., 2008).

Based on data compiled for Carlisle et al. (2013), NAWQA sites were identified that had both (1) an invertebrate community sample with an O/E ratio and (2) data for 26 pesticides analyzed in water at all sites at least 3 times during the 90 days prior to the invertebrate biological sample, with at least 2 samples occurring in different calendar months. A total of 128 stream sites sampled between 1993 and 2004 met these conditions. The potential toxicity of pesticides at these sites was characterized using the maximum Median-PTI for benthic invertebrates that occurred in samples within the 90-day time period. The relationship between O/E ratio and the Median-PTI was evaluated using least-squares regression.

\section{Results and discussion}

\subsection{Toxicity concentrations - MTC and STC}

For pesticides and degradates combined, MTCs and STCs were based on toxicity values from a total of 10,837 bioassays for 559 species in three taxonomic groups. The number of unique species was 228 for fish, 47 for cladocerans, and 284 for benthic invertebrates. Table 2 summarizes the number of compounds with toxicity values and the number of underlying bioassays for pesticides and degradates, by taxonomic group. MTC and STC values for individual pesticides and degradates in each taxonomic group are provided in Supplemental Appendix B for use in calculating PTI values from pesticide concentrations measured in environmental samples. MTC and STC values are listed for each taxonomic group separately-for fish (Table B.1), cladocerans (Table B.2), and benthic invertebrates (Table B.3)-including the number of toxicity tests, number of species, type and source of toxicity data, and any applicable bias for pesticides and degradates with non-standard toxicity data.

\subsubsection{Fish}

MTC and STC values for fish were determined for a total of 435 pesticides and 48 degradates. Many more bioassays were available for pesticides (6685) than for degradates (173; Table 2). Of the total bioassays, most (98\%; Table 2) met the definition of standard data from Table 1. The median number of standardized bioassays per compound was four for pesticides and one for degradates; the median number for non-standard bioassays was one for both pesticides and degradates. The use of non-standard data for pesticide compounds that did not have standard data available increased the total number of compounds with MTC and STC values by 78 (22\% increase) for pesticides and 18 (60\% increase) for pesticide degradates (Tables 2 and B.1). Just over half $(53 \%)$ of the pesticides and most $(83 \%)$ of the degradates with non-standard data for fish have only a single toxicity value, which means that the MTC and STC are the same for these pesticides. Overall, the standard dataset for fish includes toxicity data from 6692 bioassays representing 228 different species, including warm and cold water fish, but about half of the bioassays are for one of three species: rainbow trout (23\%), bluegill (18\%), and fathead minnow (11\%) (Appendix C, Table C.1).

\subsubsection{Cladocerans}

MTC and STC values for cladocerans were determined for a total of 423 pesticides and 47 degradates; a total of 2063 bioassays were available for pesticides and 116 for degradates (Tables 2 and B.2). The median number of bioassays per compound was one, for both standard and nonstandard data. Addition of the non-standard dataset for cladocerans increased the number of compounds with MTC and STC values by 68 (19\%) for pesticides, and 19 (68\%) for degradates (Tables 2 and B.1). There are 17 genera and 47 species represented in the standard dataset (Tables C.1 and C.2); however, most tests used D. magna (63\%), C. dubia (12\%), Daphnia pulex (5\%), Daphnia longispina or Simocephalus serrulatus ( $3 \%$ each). The non-standard cladoceran data set includes only 5 species,

Table 2

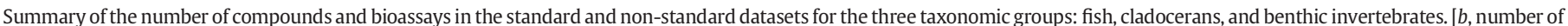
bioassays].

\begin{tabular}{|c|c|c|c|c|c|c|}
\hline \multirow[t]{2}{*}{ Bioassay data by taxonomic group } & \multicolumn{3}{|c|}{ Pesticides } & \multicolumn{3}{|c|}{ Pesticide degradates } \\
\hline & Fish & Cladocerans & Benthic invertebrates & Fish & Cladocerans & Benthic invertebrates \\
\hline No. of total compounds & 435 & 423 & 205 & 48 & 47 & 15 \\
\hline No. of total bioassays $(b)$ & 6685 & 2063 & 1734 & 173 & 116 & 66 \\
\hline Overall median $b$ per compound & 3 & 1 & 3 & 1 & 1 & 2 \\
\hline \multicolumn{7}{|l|}{ Standard data } \\
\hline No. of compounds & 357 & 355 & 139 & 30 & 28 & 10 \\
\hline No. of bioassays & 6540 & 1978 & 1571 & 152 & 97 & 53 \\
\hline Median $b$ per compound & 4 & 1 & 4 & 1 & 1 & 2 \\
\hline \multicolumn{7}{|l|}{ Non-standard data } \\
\hline No. of compounds & 78 & 68 & 66 & 18 & 19 & 5 \\
\hline No. of bioassays & 145 & 85 & 162 & 21 & 19 & 13 \\
\hline Median $b$ per compound & 1 & 1 & 1 & 1 & 1 & 2 \\
\hline Increase in no. of compounds by adding non-standard data & $22 \%$ & $19 \%$ & $47 \%$ & $60 \%$ & $68 \%$ & $50 \%$ \\
\hline
\end{tabular}


Table 3

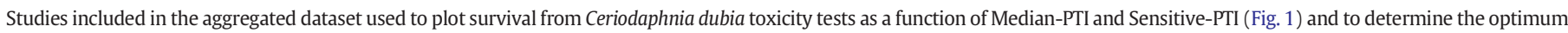

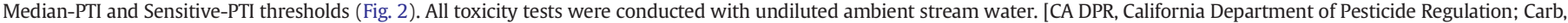

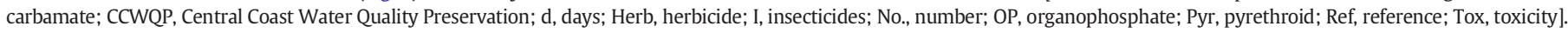

\begin{tabular}{|c|c|c|c|c|c|c|c|c|c|c|c|c|c|}
\hline \multirow{2}{*}{$\begin{array}{l}\text { Author or } \\
\text { agency }\end{array}$} & \multirow{2}{*}{$\begin{array}{l}\text { Study } \\
\text { area }\end{array}$} & \multirow{2}{*}{$\begin{array}{l}\text { No. } \\
\text { sites }\end{array}$} & \multirow{2}{*}{$\begin{array}{l}\text { No. } \\
\text { samples }\end{array}$} & \multirow{2}{*}{$\begin{array}{l}\text { Sampling } \\
\text { dates }\end{array}$} & \multicolumn{6}{|c|}{ Number of parent pesticides analyzed } & \multirow{2}{*}{$\begin{array}{l}\text { Tox test } \\
\text { duration } \\
\text { (d) }\end{array}$} & \multirow[t]{2}{*}{ General sampling design } & \multirow[t]{2}{*}{ Ref } \\
\hline & & & & & OP-I & Carb-I & Pyr-I & Other-I & Herb & Total & & & \\
\hline \multirow[t]{3}{*}{ CA DPR } & \multicolumn{13}{|c|}{ Sacramento River watershed (Wadsworth Canal) } \\
\hline & & 1 & 42 & 1998-2000 & 8 & 2 & - & - & 9 & 19 & 4 & Baseline sample in Dec, then sample twice & 1 \\
\hline & & 1 & 24 & 2000-2001 & 8 & 2 & - & - & 9 & 19 & 4 & weekly through dormant spray season & 2 \\
\hline \multirow[t]{4}{*}{ CA DPR } & \multicolumn{13}{|c|}{ San Joaquin River watershed (Orestimba Creek) } \\
\hline & & 1 & 18 & 1997-1998 & 8 & 2 & - & - & 9 & 19 & 4 & Baseline sample in Dec, then sample twice & 3 \\
\hline & & 1 & 20 & 1998-1999 & 8 & 2 & - & - & 9 & 19 & 4 & weekly through dormant spray season & 4 \\
\hline & & 1 & 20 & 1999-2000 & 8 & 2 & - & - & 9 & 19 & 4 & & 5 \\
\hline \multirow[t]{2}{*}{ CA DPR } & \multicolumn{13}{|c|}{ Del Puerto and Orestimba Creeks } \\
\hline & & 2 & 21 & 2007-2008 & 10 & - & 8 & - & - & 18 & 4 & $\begin{array}{l}\text { Monthly samples from Dec-June; } 3 \text { storm } \\
\text { samples in Dec, Jan, Feb }\end{array}$ & 6 \\
\hline \multirow[t]{5}{*}{ CA DPR } & \multicolumn{13}{|c|}{ Orange County } \\
\hline & & 3 & 8 & 1999 & 8 & - & - & - & - & 8 & 4 & Rainfall runoff sampling & 7 \\
\hline & & 12 & 90 & 1999-2000 & 8 & - & 1 & 3 & - & 12 & 4 & $\begin{array}{l}\text { Monthly sampling; Feb } 2000 \text { samples } \\
\text { coincided with rainfall }\end{array}$ & 8 \\
\hline & & 8 & 38 & 2000 & 8 & - & 1 & 3 & - & 12 & 4 & Rainfall runoff sampling & 9 \\
\hline & & 2 & 14 & 2000-2001 & 5 & - & 1 & 3 & - & 9 & 4 & Monthly sampling; no rainfall runoff & 10 \\
\hline \multirow[t]{5}{*}{ CCWQP } & \multicolumn{13}{|c|}{ Lower Salinas and Santa Maria watersheds } \\
\hline & & 18 & 18 & 2007 & 19 & - & - & - & - & 19 & $6-8 \mathrm{~d}$ & Sample during dry season & 11 \\
\hline & & 4 & 6 & 2008 & 14 & 6 & - & - & 7 & 27 & $6-8 d$ & Sample during dry season & 11 \\
\hline & & 21 & 21 & 2008 & 19 & - & - & - & - & 19 & $6-8 d$ & Sample during dry season & 11 \\
\hline & & 23 & 94 & $2006-2007$ & 19 & - & - & - & - & 19 & $6-8 d$ & $\begin{array}{l}\text { Sample twice per year in dry } \\
\text { season and twice in winter/wet season }\end{array}$ & 12 \\
\hline \multirow[t]{2}{*}{ Kuivila } & \multicolumn{13}{|c|}{ San Francisco Estuary } \\
\hline & & 2 & 35 & 1993 & ${ }^{a} 4$ & ${ }^{a} 1$ & - & - & $a_{3}$ & 8 & $7 \mathrm{~d}$ & $\begin{array}{l}\text { Daily samples for } 3 \text { weeks; } \\
\text { included some rainfall events }\end{array}$ & 13 \\
\hline \multirow[t]{2}{*}{ Phillips } & \multicolumn{13}{|c|}{ Santa Maria River and Oso Flaco Creek watersheds } \\
\hline & & 10 & 10 & 2009 & 6 & - & 9 & - & - & 15 & 4 & $\begin{array}{l}\text { Bimonthly for } 1 \text { year; full pesticide analysis } \\
\text { on } 1 \text { sample per site }\end{array}$ & 14 \\
\hline
\end{tabular}

a 19 pesticides analyzed but only those detected were identified

1. Nordmark (1999, 2000)

2. Gill (2002)

3. Ganapathy (1999a)

4. Ganapathy (1999b)

5. Jones (2000)

6. Ensminger et al. (2009)

7. Kim et al. (1999a)
8. Kim et al. (1999b); Walters et al. (2000c); Walters et al. (2000e, f, g, h, i, j, k, m)

9. Walters et al. (20001)

10. Walters et al. (2000a, b, d, 2001a, b, c, d, e, f, g, h, i, j)

11. Central Coast Water Quality Preservation Inc. (2009)

12. Central Coast Water Quality Preservation Inc. (2008)

13. Kuivila and Foe (1995)

14. Phillips et al. (2012) and D. magna accounts for $90 \%$ of the non-standard bioassays (Table C.1).

\subsubsection{Benthic invertebrates}

MTC and STC values for benthic invertebrates were determined for 205 pesticides and 15 degradates from a total of 1734 bioassays for pesticides and 66 bioassays for degradates (Tables 2 and B.3). Addition of the non-standard data for benthic invertebrates increased the number of compounds with MTC and STC values by 66 (47\%) for pesticides and 5 (50\%) for degradates. The standard dataset had 3 or more bioassays for $59 \%$ of compounds and represented 259 species, with amphipods of the genus Gammarus making up nearly 20\% of the standard bioassays (Tables B.3 and C.1). The non-standard dataset for benthic invertebrates included toxicity data from 44 different species (Table C.1), with the greatest number of bioassays for the midge, C. riparius ( $16 \%$ of the total), followed by the mosquito, Aedes aegypti (9\%) and crayfish, Procambarus clarkii (8\%). Collectively, the standard and non-standard benthic invertebrate datasets include data for 284 species and 172 genera. Benthic crustaceans account for $25 \%$ of the genera and $33 \%$ of the species; insects/spiders account for $47 \%$ and $38 \%$, and molluscs account for $28 \%$ and $28 \%$ of the genera and species, respectively (Table C.2).

\subsection{PTI values for a water sample}

MTC and STC values for individual pesticide compounds in Supplemental Appendix Tables B.1 to B.3 can be used with Eq. (1) to calculate Median-PTI and Sensitive-PTI values, respectively, for a sample. Pesticide compounds with non-standard MTC and STC values have greater uncertainty compared to compounds for which standardized toxicity test data are available, but the decision to exclude that pesticide from the PTI because it has a non-standard MTC or STC is equivalent to treating it as a non-detection in the sample. For some applications, it may be preferable to include an uncertain or biased toxicity value (i.e., non-standard MTC or STC value) for a given pesticide, in lieu of leaving that pesticide out of the PTI. However, potential bias of pesticides with non-standard data should be considered when applying the PTI to interpret water-quality data, especially if a pesticide with a nonstandard MTC that is biased low (i.e., overestimates toxicity) tends to dominate the PTI of a water sample.

MTC and STC values are significantly correlated with one another $(\mathrm{p}<0.001)$ within a taxonomic group ( $\mathrm{R}^{2}$ of 0.84 to 0.93 ). The ratio of MTC to STC values for a given pesticide reflects the degree of variability in the toxicity data available for that pesticide. The MTC/STC ratios vary the least for cladocerans (coefficient of variation, $C V=400 \%$ ), the group containing the smallest number of unique species. Fish are 
intermediate ( $\mathrm{CV}=500 \%$ ) and benthic invertebrates, which is the most diverse taxonomic group, have the most variable MTC/STC ratios ( $\mathrm{CV}=1,100 \%$ ). The MTC/STC ratio is 10 or higher for $9 \%$ of pesticides for cladocerans, $15 \%$ of pesticides for fish, and $22 \%$ of pesticides for benthic invertebrates. The Median-PTI dampens differences in toxicity values among taxa, tests, and test conditions, and provides a measure of central tendency for comparing the toxicity of one pesticide to another towards a given taxonomic group.

When MTCs (medians) are used, the purpose of the index is to represent the relative toxicity of sites, samples, or individual pesticidesMTC values may be higher than effect concentrations for some species and life stages in a given hydrologic system, but they are relatively robust to outliers. When the STC values are used, the index is better suited for use as a screening level, because it is a more conservative (protective) indicator of the potential for toxicity. Although the 5th percentile of the available toxicity values was selected as the basis for the Sensitive-PTI (as discussed in Section 2.4), it does not necessarily protect $95 \%$ of species and it is not equivalent to a 5 th-percentile hazardous concentration (HC5) from a SSD (Etterson, 2011). The PTI methodology computes the 5th (and 50th) percentiles of all suitable independent toxicity tests, whether tests are based on the same species or on different species. It is intended to prevent low outlier values, such as from singularly sensitive species, statistically anomalous results, or unusual test conditions, from skewing the results.

\subsection{Example applications of the PTI to interpret water-quality data}

\subsubsection{Validation test of the PTI using aggregated data from published studies}

Data aggregated from published studies were used to test how well the PTI approach predicted the incidence of observed toxicity, (i.e., reduction in C. dubia survival). The available studies (Table 3), which analyzed different numbers and classes of pesticides at different analytical reporting levels, are not considered to represent a robust test of the PTI model. However, these results provide some indication of PTI values at which toxicity has been observed in field-collected water samples.

Based on aggregated data from published studies (Table 3 and Supplemental Appendix D), Fig. 1 shows survival of C. dubia in 4-8 day toxicity tests in ambient stream water as a function of the Median-PTI (Fig. 1A) and the Sensitive-PTI (Fig. 1B). With some exceptions (those symbols shown on y-axis), survival remained near 100\% until the Median-PTI reached about 0.1. Survival rates decreased sharply at Median-PTI values between about 0.1 and 0.5 , with highly variable \% survival within this range. Of samples with Median-PTI values $>1,97 \%$ had $C$. dubia survival reduced to $\leq 50 \%$ relative to controls, and $96 \%$ had $0 \%$ survival. Percent survival declined to $50 \%$ well below the theoretical value of 1 for the Median-PTI. The same studies plotted in relation to the Sensitive-PTI look very similar (Fig. 1B), except that most results are shifted to the right, so that $C$. dubia survival appears to drop at Sensitive-PTI values between 0.5 and 1 . Results were similar among studies and no single study dominated the pattern shown.

The pattern shown in Fig. 1 was the same for studies that exposed C. dubia to ambient water for 4 days vs. 6-8 days and also for studies that measured only organophosphate insecticides vs. multiple classes of pesticides (not shown). Organophosphates accounted for over half of the Median-PTI in $71 \%$ of samples overall, and in $86 \%$ of samples with $C$. dubia survival reduced to $\leq 50 \%$. This occurred in part because organophosphates are highly toxic, but also because most of the published studies had focused on organophosphate insecticides because of CWA $\S 303(d)$ listing of streams. Where organophosphates were the only pesticides analyzed (141 samples) or the only pesticides detected (110 additional samples), the PTI model is indistinguishable from an organophosphate TU model, in which only pesticides with this common mode of action (acetylcholinesterase inhibition) are included. However, of 228 samples with multiple pesticide classes detected, 81 samples had
(A)

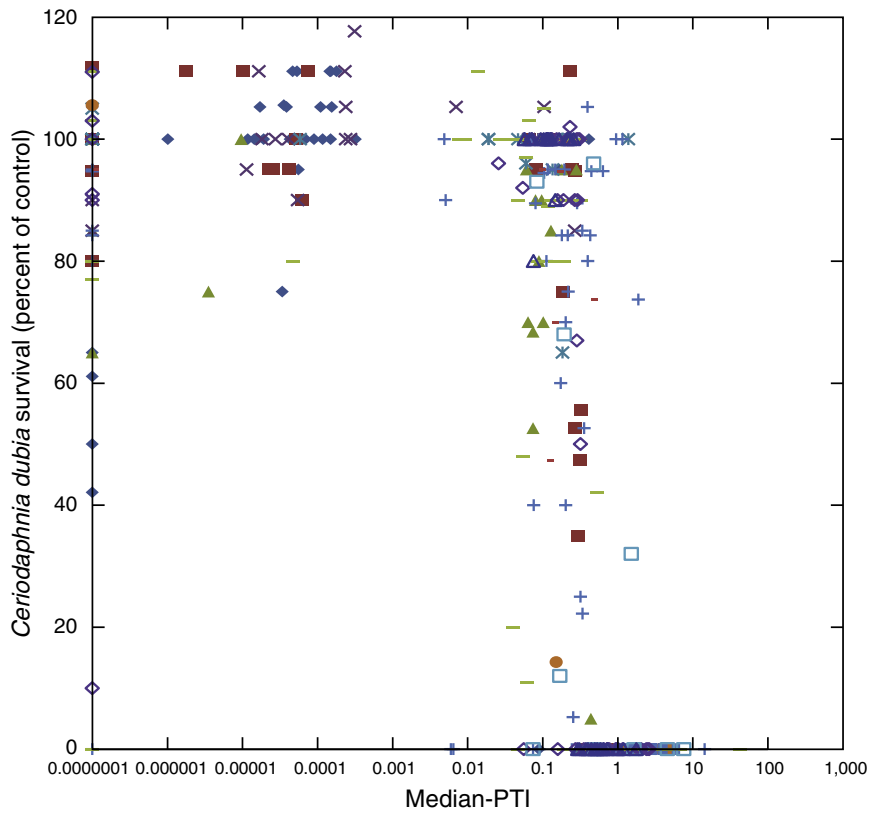

(B)

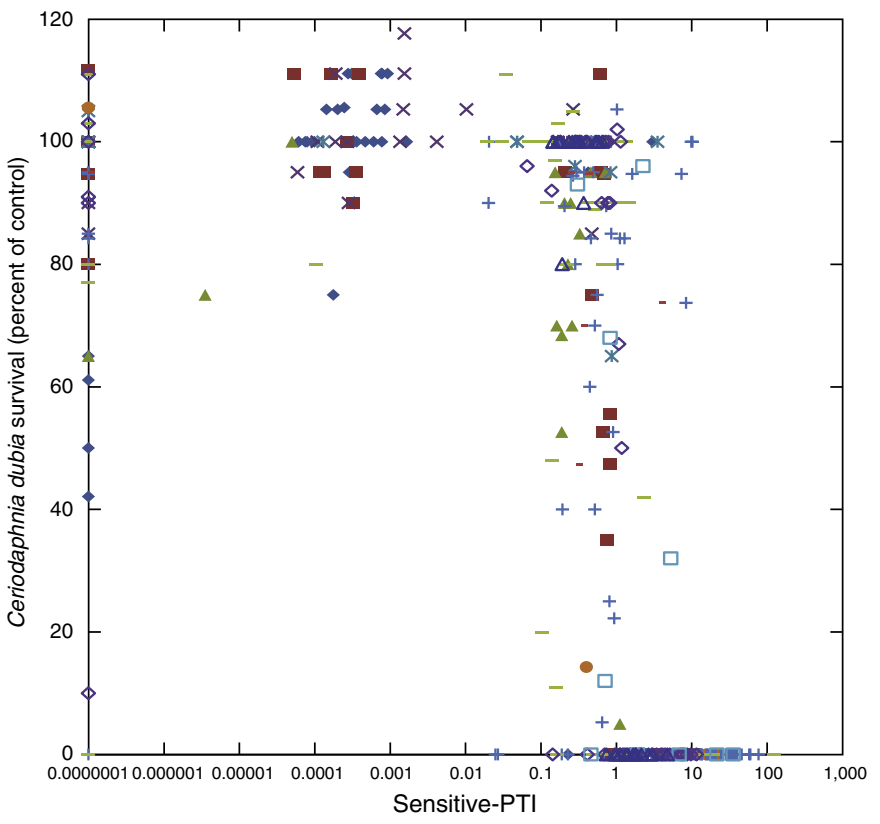

\begin{tabular}{|c|c|c|c|}
\hline \multicolumn{4}{|r|}{ EXPLANATION } \\
\hline$\bullet$ & Ganapathy $(1999 a, b)$ & + & Kim et al. (1999b), Walters et al. (2000c, e-m) \\
\hline घ & Nordmark $(1999,2000)$ & - & Walters et al. (2000a, b, d, 2001a-m) \\
\hline$\Delta$ & Gill (2002) & & CCWQP (2008) \\
\hline$x$ & Jones (2000) & & CCWQP (2009) \\
\hline * & Ensminger et al. (2009) & & Phillips et al. (2009) \\
\hline$\bullet$ & Kim et al. (1999a) & & Kuivila and Foe (1995) \\
\hline
\end{tabular}

Fig. 1. Ceriodaphnia dubia survival on 4-8 day exposure to ambient water, as a function of Median-Pesticide Toxicity Index (PTI) (A) and Sensitive-PTI for cladocerans (B), computed for pesticides detected in the sample. Each symbol represents a single sample ( $n=479$ samples). Results are aggregated from published studies in Table 3.

C. dubia survival reduced to $\leq 50 \%$. In these 81 "toxic" samples, organophosphates accounted for less than half of the Median-PTI in 32\% of samples, and less than one quarter of the Median-PTI in $17 \%$ of 
samples-indicating that other pesticides besides organophosphates may have contributed to the observed toxicity in these samples.

The incidence of toxicity in samples with Median-PTI values $<1$ is expected because the lowest toxicity values were excluded by use of the median, pesticides may be present at concentrations below the analytical detection level, and contaminants may have been present that were not analyzed in the sample or that were not included (because toxicity data were not available) in the PTI. In addition, variability is expected because of uncertainty in MTCs used to compute PTI values, deviation from the CA model that underlies the PTI approach, and environmental factors affecting toxicity in the sample. Lack of toxicity at Median-PTI values $>1$ is more difficult to explain, but this occurred in only 3 samples from 2 studies, out of a total of 479 samples. Possible explanations include the fact that dose-response curves vary for different pesticides and mortality occurs at concentrations below the EC50 or LC50 endpoints used to derive MTCs; use of the MTC to represent a given pesticide, which may underestimate toxicity to some organisms and overestimate toxicity to others; the assumption that toxicity is additive with no chemical interaction for pesticides from multiple classes with different modes of action; and the fact that the PTI does not consider environmental factors (e.g., organic carbon, temperature) that may affect bioavailability and(or) toxicity.

In summary, although data available to test the PTI model are limited, C. dubia survival was reduced to $\leq 50 \%$ of controls in $44 \%$ of samples with Median-PTI values in the range of 0.1 to 1 , and to $0 \%$ in $96 \%$ of samples with Median-PTI values $>1$. For the Sensitive-PTI, C. dubia survival was reduced to $\leq 50 \%$ of controls in $81 \%$ of samples in the range of 0.1 to 1 , and in $89 \%$ of samples with Sensitive-PTI values $>1$.

In theory, for TUs that are based on acute LC50/EC50 data, the CA model predicts $50 \%$ mortality at a theoretical threshold of 1 , and theoretically based thresholds were proposed in previous studies by Battaglin and Fairchild (2002) and Anderson (2008) for classifying samples according to the probability of toxicity from pesticide mixtures. In contrast, an empirical threshold was previously developed for contaminant mixtures in sediment (Ingersoll et al., 2001; MacDonald et al., 2000) on the basis of validation data from field studies, which indicated a high probability of toxicity at values $>0.5$ for an additive sedimentquality index called the Mean Probable Effect Concentration Quotient. Similarly, in the present study, the validation dataset consisting of field data on pesticides and C. dubia survival (Table 3 and Supplemental Appendix D) can be used to determine an apparent empirical threshold at which the PTI model best explains the incidence of toxicity observed in the reviewed studies, but in this case the "threshold" is actually based on a 50\%-mortality response. An empirical threshold of toxicity should result in the correct classification of as many samples as possible-so that all or most of the samples above the empirical threshold are toxic, and all or most of the samples below the threshold are nontoxichowever "toxic" may be defined.

Fig. 2 shows the percentage of samples in the aggregated dataset that were correctly classified as "toxic" or "nontoxic," as a function of various possible 50\%-mortality threshold values for Median-PTI and Sensitive-PTI. In the analysis shown in Fig. 2, toxicity was defined as reducing C. dubia survival to $\leq 50 \%$ of controls, or $50 \%$ mortality, because this corresponds to the definition of LC50 and EC50 on which the cladoceran Median-PTI and Sensitive-PTI are based. Correspondingly, "nontoxic" is used to indicate survival $>50 \%$ relative to control. Correct classification is defined as the sum of (i) the number of samples with PTI above a potential 50\%-mortality threshold and also toxic (as defined above), plus (ii) the number of samples with PTI below the threshold and nontoxic, as a percentage of (iii) the total number of samples. It is important to acknowledge that the potential 50\%-mortality thresholds under discussion designate index levels at which $C$. dubia survival was reduced to $\leq 50 \%$, whereas in actuality, mortality and sublethal toxicity will occur at levels below LC50 and EC50 values.

In Fig. 2, each symbol represents all the data ( $n=479$ samples) assessed relative to the corresponding possible $50 \%$-mortality threshold

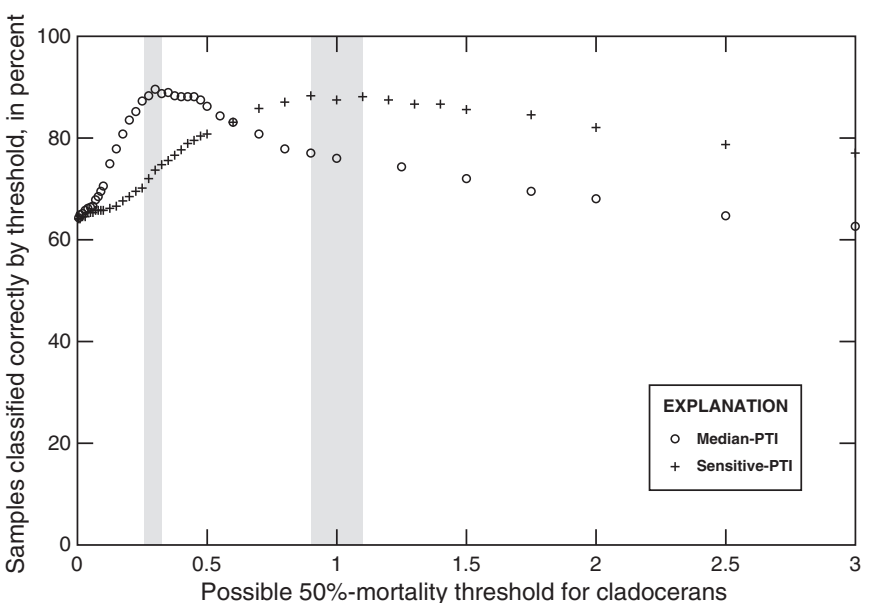

Fig. 2. Effectiveness of various 50\%-mortality thresholds for the Pesticide Toxicity Index (PTI) in correctly classifying samples in the aggregated dataset as nontoxic or toxic. Each symbol shows the percentage of samples in the entire dataset $(n=479)$ that was correctly classified using the threshold value on the $\mathrm{x}$-axis. The gray-shaded areas indicate the optimum $50 \%$-mortality threshold range (x-axis value corresponding to the maximum $\mathrm{y}$-axis value) for the Sensitive-PTI and Median-PTI.

on the $\mathrm{x}$-axis. The $\mathrm{x}$-axis represents the possible $50 \%$-mortality threshold values ranging from 0.01 to 3 , and the y-axis indicates how well each threshold value performed in explaining $C$. dubia mortality in the aggregated dataset. At low 50\%-mortality threshold values, the correct classification rate is low because a large proportion of samples above these low thresholds were nontoxic. As increasingly higher values for the 50\%-mortality threshold values are considered, fewer of the samples above the threshold are nontoxic, so the percentage of samples that were correctly classified increases to a maximum. As potential $50 \%$ mortality threshold values continue to increase above the level associated with this maximum, the number of toxic samples below the threshold begins to increase, causing the frequency of correct classification to decline. The optimum 50\%-mortality threshold for correct classification of samples in this dataset-that is, the value resulting in the maximum percentage of correctly classified samples-is 0.3 for the Median-PTI and $0.9-1.1$ for the Sensitive-PTI (Fig. 2).

The 50\%-mortality thresholds of 0.3 and about 1 for Median-PTI and Sensitive-PTI, respectively, are empirical thresholds that apply only to the studies on which they were based. Although in this analysis, toxicity was defined as reduction of $C$. dubia survival to $\leq 50 \%$ of controls during a 4-8 day exposure, the results were similar when toxicity was defined as reducing survival to $\leq 70 \%$ of that of controls (the optimum $70 \%$-mortality threshold for the Median-PTI was still 0.3 ) or $\leq 40 \%$ of that of controls (the optimum 40\%-mortality threshold for the Median-PTI was $0.35)$. This indicates robustness in the analysis, in that an empirical "mid-level" mortality threshold was not strongly influenced by the exact percentage survival used to define a "toxic" sample. Because the empirical 50\%-mortality thresholds for the Median-PTI and SensitivePTI predict about $50 \%$ mortality, it is likely that some toxicity-some degree of reduced survival, sublethal effects, and(or) adverse effects on invertebrate communities-will occur at lower index levels.

Whether the empirical 50\%-mortality thresholds derived here would successfully predict mortality in future studies of large numbers of pesticides from multiple classes is uncertain because (1) this analysis is based on a limited number of samples (479); (2) the studies on which this analysis is based each determined a relatively small number of pesticides ( 8 to 27 per study); (3) many of these studies were focused on organophosphate insecticides, which share a common mode of action and have been shown to exhibit additive toxicity to cladocerans (Bailey et al., 1997); and (4) concentrations of organophosphate insecticides have decreased in streams (Ryberg et al., 2010; Sullivan et al., 2009) since USEPA restricted their uses in both agricultural and urban applications (U.S. Environmental Protection Agency, 2000, 2001), 
whereas concentrations of insecticides in other classes, including carbaryl, pyrethroids, and fipronil, have increased (Ryberg et al., 2010).

\subsubsection{Determination of potentially toxic pesticides in a watershed}

Results from one of the studies in Table 3 (and included in the aggregated dataset in Section 3.3.1 and Appendix D) are used as an example to illustrate the application of the PTI to interpret water quality data. In this study of dormant-spray pesticides and associated water toxicity conducted by the California DPR, water samples were collected from the Sacramento River watershed at Wadsworth Canal, a tributary of the Sutter Bypass, which receives inflow from dormant spray areas and has no major inputs from municipal or industrial sources (Gill, 2002; Nordmark, 1999, 2000). Samples were collected in December, prior to the onset of dormant spray season, and again during January to March, continuing until dormant spray had ceased, for three consecutive years (1998-2001). The parent pesticides analyzed were 8 organophosphate insecticides, 2 carbamate insecticides, and 9 herbicides. Acute toxicity to $C$. dubia was measured in 4-day static renewal tests.

Median-PTI and Sensitive PTI values for cladocerans were calculated using Eq. (1) and the pesticide concentrations reported in the California DPR study. Data from the first two years (the first 42 of the 66 total samples) of the Wadsworth Canal study (Nordmark, 1999, 2000) are shown in Fig. 3. Total pesticide concentrations (Fig. 3A) tended to be low in December, and the herbicide diuron was the only pesticide detected. The number of unique pesticides detected increased to seven during the spray season, with total pesticide concentrations peaking in late January and February (Fig. 3A). Median-PTI values also peaked in late January and February (Fig. 3B) and were dominated by diazinon, with minor contributions from methidathion in some samples. The same pattern was observed for Sensitive-PTI (Fig. 3C), except that the scale of PTI values was higher and the contribution of methidathion was barely visible. Although the herbicides simazine, hexazinone, diuron and bromacil combined to account for a third to half of the summed concentrations of pesticides detected during the dormant spray season, organophosphates accounted for over 99\% of the Median-PTI for samples in which $C$. dubia survival was $\leq 50 \%$. Toxicity was observed in samples with Median-PTI greater than about 0.3 and Sensitive-PTI greater than about 0.8 . The percent survival of $C$. dubia at the Wadsworth Canal site over the 3-year study (Fig. 3D) was significantly correlated with both the Median-PTI and the Sensitive-PTI ( $p<0.0001$, Spearman rho $=$ -0.67 ), which each explained $43 \%$ of the variability in \% survival in separate least-squares regressions. The relationship also was significant for the summed TUs for organophosphate insecticides only $(\mathrm{p}<0.0001$, Spearman rho $=-0.68)$, which explained $37 \%$ of the variability in \% survival. PTI analysis, such as that shown here, can aid in determining which sites, samples, or pesticides are the most important in terms of potential toxicity to aquatic organisms.

\subsubsection{Invertebrate community condition in streams across the U.S.}

Median-PTI values for benthic invertebrates were calculated for pesticide concentrations detected in water at 128 stream sites across the U.S. sampled during 1993-2004 by the USGS NAWQA Program. MTC values were available for 20 of the 26 pesticides analyzed in these samples. Macroinvertebrate community condition, characterized by the $\mathrm{O} / \mathrm{E}$ ratio at the same 128 stream sites, was analyzed relative to the maximum Median-PTI for benthic invertebrates occurring within the 90-days prior to the date of the invertebrate sample, as described in Section 2.5. The O/E ratio is a measure of biodiversity. An O/E ratio of 1 indicates that the measured invertebrate composition is equal to the expected composition (U.S. Environmental Protection Agency, 2006), with ratios $<0.8$ indicating biological degradation (Carlisle and Meador, 2007). There was a significant inverse relationship between $\mathrm{O} / \mathrm{E}$ and the Median-PTI ( $\mathrm{p}=0.01$, not shown), but the Median-PTI explained only $5 \%$ of the variability in $\mathrm{O} / \mathrm{E}$ ratios (biodiversity). This small amount of variability explained is not unexpected because invertebrate community condition in streams is affected by many factors in addition to pesticide contamination, including other chemical stressors (e.g., nutrients, salinity, acidification, hydrophobic contaminants in sediment), physical stressors (e.g. sediment, temperature, flow alteration, habitat degradation) and biological stressors (e.g. invasive or non-native species), as frequently noted in the literature (e.g., Bryant and Carlisle, 2012; Carlisle et al., 2013; Tate and Heiny, 1995; U.S. Environmental Protection Agency, 2006).

\subsection{Limitations}

The PTI has several limitations, which must be carefully considered in applications:

- The PTI is a relative ranking system that indicates that one sample is likely to be more or less toxic than another sample, but does not indicate that toxicity will necessarily occur.

- Toxicity values are based on short-term laboratory experiments with EC50 (nonlethal response) or LC50 (mortality) endpoints; the PTI does not reflect long-term/chronic exposure or (except for immobilization in cladocerans) incorporate sublethal endpoints.

- The PTI does not account for environmental factors, such as dissolved organic carbon, particulates, $\mathrm{pH}$, and temperature, which can affect the toxicity and bioavailability of pesticides.

- The PTI assumes that pesticide toxicity is additive and there is no chemical interaction (synergism or antagonism), which may not be the case for complex mixtures of pesticides from different chemical classes and with different MOAs across all taxonomic groups and life stages.

- The PTI does not take into account the dose-response curves of either single-chemical or mixtures exposures.

- The PTI is limited to pesticides measured in the water column; hydrophobic pesticides may be underrepresented in terms of potential toxicity, especially to benthic organisms.

- Uncertainty in the relative toxicity of compounds is high for pesticides with relatively few bioassays available. The 10,837 bioassays in this data set are divided among 440 pesticides and 52 degradates, 559 different species, and three taxonomic groups, making the number in each group relatively small. Although this does not preclude the use of the data as the best available, it demonstrates the sparseness of available data on the toxicity of many currently used pesticides.

- Most data are for standard test species (rainbow trout, bluegill, and fathead minnow for fish, and daphnids for invertebrates). Analysis of SSDs for pesticides showed that values for the three typical OPP test species (rainbow trout, bluegill, and D. magna) typically resulted in smaller HC5 values (i.e., indicating greater toxicity) compared to random subsets of three toxicity values for the available test species (Etterson, 2011).

- Many factors contribute to the high variability observed in laboratory toxicity tests, including formulation of the pesticide; test species, age and condition of individual organisms used; water conditions $(\mathrm{pH}$, temperature, concentration and type of dissolved organic carbon); testing environment (flow-through or static); and whether test organisms are fed during exposure (Jonczyk and Gilron, 2005; Persoone et al., 2009). For applications in which certain individual compounds are particularly important, special attention should be given to the variability in toxicity test results for those compounds.

\section{Conclusions}

The PTI is a relative, but quantitative, indicator of potential toxicity that can be used in study design or to interpret water quality data, relate pesticide exposure to biological condition, and prioritize future assessments. The PTI uses toxicity concentrations available for 440 pesticides (out of a total of 484 pesticides with reported agricultural use during 1992 to 2011) and 52 pesticide degradates. Combined, the toxicity data for pesticides and 

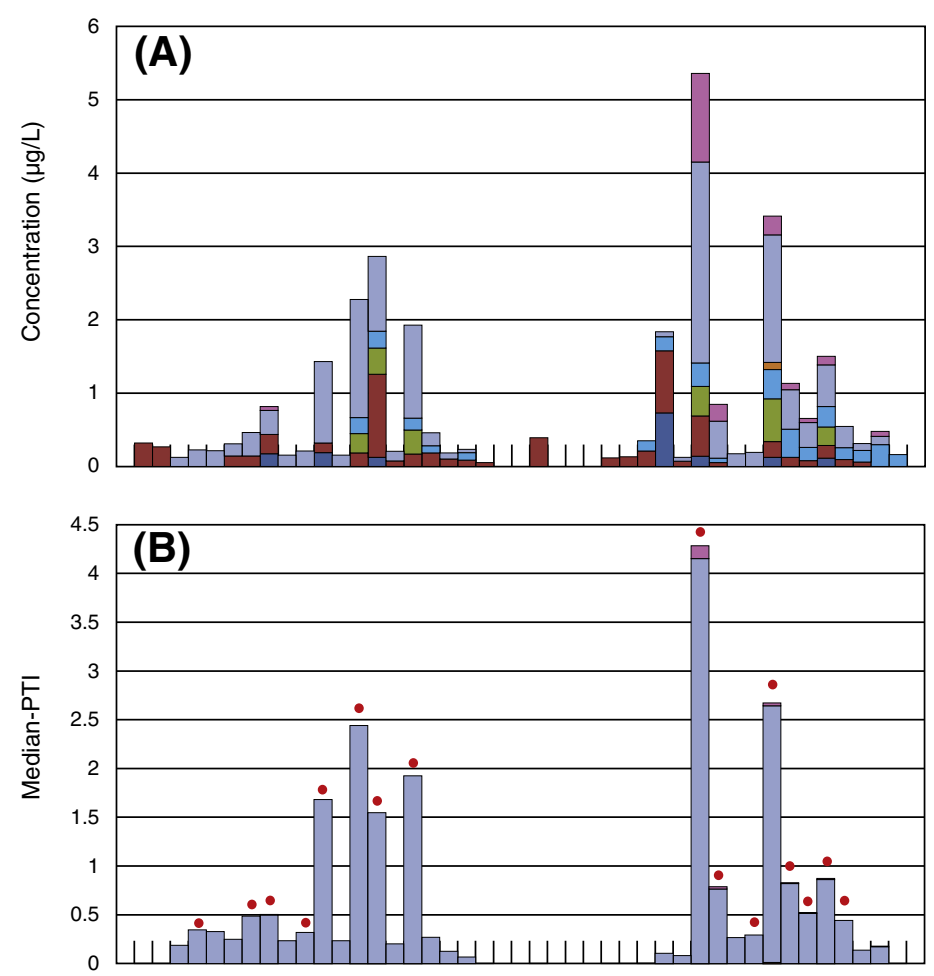

\begin{tabular}{|l|}
\hline \multicolumn{1}{|c|}{ EXPLANATION } \\
$\square$ Methidathion \\
$\square$ Diazinon \\
$\square$ Carbaryl \\
$\square$ Simazine \\
$\square$ Hexazinone \\
$\square$ Diuron \\
$\square$ Bromacil \\
Ceriodaphnia dubia \\
survival (part D only) \\
- $\leq \mathbf{5 0 \%}$ Survival \\
\hline
\end{tabular}
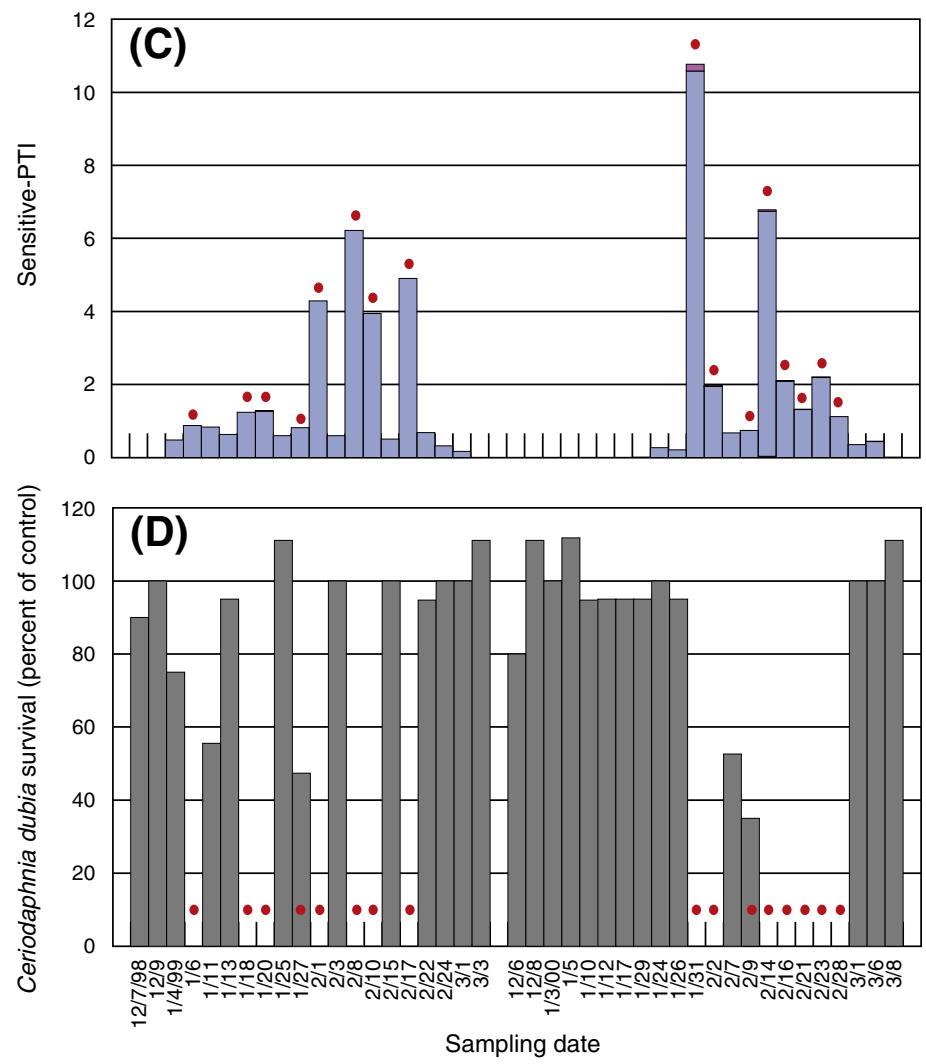

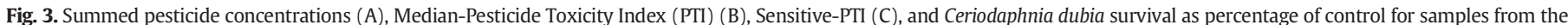

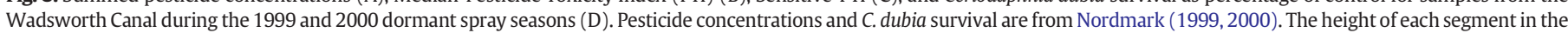

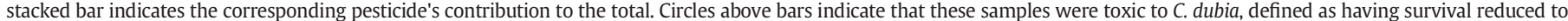
$\leq 50 \%$ relative to control after 4 -day exposure.

degradates include 10,837 bioassays representing 559 different species in three taxonomic groups. Toxicity endpoints include LC50 for fish, EC50 or LC50 for cladocerans, and LC50 or EC50 for benthic invertebrates.
Two types of PTI, as described herein, can be calculated for a field sample. The Median-PTI is calculated using median toxicity concentrations for each pesticide in a sample mixture. The Sensitive-PTI uses the 5th percentile of toxicity concentrations (except that the minimum is 
substituted for pesticides with small data sets). The Median-PTI approach is more robust to outliers, whereas the Sensitive-PTI may be appropriate for applications in which a conservative comparison to a screening level is needed.

To test the PTI model, data on concurrent pesticide concentrations and toxicity to $C$. dubia in ambient stream water were aggregated from published field studies, PTI values were calculated, and empirical 50\%-mortality thresholds for the Median-PTI and Sensitive-PTI were determined to be about 0.3 and 1, respectively. These 50\%-mortality thresholds correctly predicted toxicity (defined as $\geq 50 \%$ mortality) or nontoxicity ( $<50 \%$ mortality) in about $90 \%$ of samples in the reviewed studies. Although field data are not available to validate the PTI model for a comprehensive range of pesticides, the analysis of available data described here indicates that substantial mortality may occur at Median-PTI values in the range of 0.1 to 1 -based on the observation that $\geq 50 \%$ mortality to $C$. dubia occurred in only $6 \%$ of samples from the aggregated dataset with Median-PTI values $<0.1$, but in $44 \%$ of samples in the 0.1 to 1 range. Mortality likely would be high at Median-PTI values $>1$, where $96 \%$ of samples in the aggregated validation data set showed $100 \%$ mortality to C. dubia. For the Sensitive-PTI, the percentage of samples with $\geq 50 \%$ mortality was $5 \%$ in samples with Sensitive-PTI values $<0.1,19 \%$ in the 0.1 to 1 range, and $89 \%$ at Sensitive-PTI values $>1$

The PTI can be applied to pesticide mixtures detected in ambient water samples, and PTI values for individual water samples then can be used to rank sites according to their expected relative potential toxicity caused by pesticides, to assess changes in potential toxicity over time at a single site, or to predict which of the pesticides detected may be the biggest contributor to potential toxicity for the sample or site. PTI values for samples, seasons, or sites also can be used as explanatory variables in multivariate analysis designed to determine which environmental variables best explain spatial patterns in the structure of a biological community. A more rigorous test of the PTI model is needed, but this will require the availability of data for pesticides from multiple classes and modes of action, concurrent with data on aquatic toxicity and(or) ecological condition.

Supplementary data to this article can be found online at http://dx doi.org/10.1016/j.scitotenv.2013.12.088.

\section{Disclosure statement}

None of the authors have any actual or potential conflict of interest including any financial, personal or other relationships with other people or organizations within three years of beginning the submitted work that could inappropriately influence, or be perceived to influence, their work.

\section{Acknowledgments}

The authors thank USGS personnel for collecting and analyzing stream water samples and biological samples. We also thank Jerry Tran (USGS) for his assistance with graphics, Daren Carlisle (USGS) for providing NAWQA biological data, and Robert Gilliom (USGS), Wade Bryant (USGS), and two anonymous reviewers for their helpful insights and reviews.

\section{References}

Anderson A-M. Development of an aquatic pesticide toxicity index for use in Alberta Edmonton, Alberta: Alberta Environment, Environmental Assurance; 2008W0803 [30 pp.].

Backhaus T, Faust M. Predictive environmental risk assessment of chemical mixtures: conceptual framework. Environ Sci Technol 2012:46:2564-73.

Bailey H, Miller J, Miller M, Wiborg L, Deanovic L, Shed T. Joint acute toxicity of diazinon and chlorpyrofios to Ceriodaphnia dubia. Environ Toxicol Chem 1997;16:2304-8.

Battaglin W, Fairchild J. Potential toxicity of pesticides measured in Midwestern streams to aquatic organisms. Water Sci Technol 2002;45:95-103.
Belden JB, Gilliom RJ, Lydy MJ. How well can we predict the toxicity of pesticide mixtures to aquatic life? Integr Environ Assess Manag 2007;3:364-72.

Bliss CI. The toxicity of poisons applied jointly. Ann Appl Biol 1939;26:585-615.

Bryant WL, Carlisle DM. The relative importance of physicochemical factors to stream biological condition in urbanizing basins: evidence from multimodel inference. Freshw Sci 2012;31:154-66.

Carlisle DM, Hawkins CP. Land use and the structure of western US stream invertebrate assemblages: predictive models and ecological traits. JN Am Benthol Soc 2008;27: 986-99.

Carlisle DM, Meador MR. A biological assessment of streams in the eastern united states using a predictive model for macroinvertebrate assemblages. J Am Water Resour Assoc 2007:43:1197-207.

Carlisle DM, Meador MR, Short TM, Tate CM, Gurtz ME, Bryant WL, et al. The quality of our Nation's waters-ecological health in the Nation's streams, 1993-2005. Circular. Reston, VA: U.S. Geological Survey; 20131391 [120 pp.].

Cedergreen N, Streibig JC. Can the choice of endpoint lead to contradictory results of mixture-toxicity experiments? Environ Toxicol Chem 2005;24:1676-83.

Cedergreen N, Christensen AM, Kamper A, Kudsk P, Mathiassen SK, Streibig JC, et al. A review of independent action compared to concentration addition as reference models for mixtures of compounds with different molecular target sites. Environ Toxicol Chem 2008;27:1621-32.

Central Coast Water Quality Preservation Inc.. Phase I follow-up water quality monitoring: organophosphate pesticide sampling final data report. Central Coast Region Conditional Ag Waiver Cooperative Monitoring Program; 2008 [37 pp.].

Central Coast Water Quality Preservation Inc.. Supplemental water quality monitoring for organophosphate pesticides and aquatic toxicity. Central Coast Region Conditional Ag Waiver Cooperative Monitoring Program; 2009 [24 pp.].

Commission of the European Communities. Commission Directive 92/69/EEC of 31 July 1992 adapting to technical progress for the 17th time Council Directive 67/548/EEC on the approximation of laws, regulations and administrative provisions relating to the classification, packaging and labelling of dangerous substances. C.2. Acute toxicity test Daphnia. Commission of the European Communities; 1992.

Cunnane C. Unbiased plotting positions-a review. J Hydrol 1978;37:205-22.

de Zwart D, Posthuma L. Complex mixture toxicity for single and multiple species: proposed methodologies. Environ Toxicol Chem 2005;24:2665-76.

Deneer JW. Toxicity of mixtures of pesticides in aquatic systems. Pest Manag Sci 2000;56: 516-20.

Ensminger M, Bergin R, Spurlock F. Pesticide concentrations in water and sediment and associated invertebrate toxicity in Del Puerto and Orestimba Creeks, California. Sacramento, CA: California Environmental Protection Agency, Department of Pesticide Regulation; 2009 [47 pp.]

Etterson M. Analyses of sensitivity distributions for estimation of acute hazard concentrations to aquatic animals. Appendix C of USEPA, review of methods for characterizing effects of pesticides and other chemical stressors to aquatic organisms. U.S. Environmental Protection Agency; 2011.

Faust M, Altenburger R, Boedeker W, Grimme LH. Algal toxicity of binary combinations of pesticides. Bull Environ Contam Toxicol 1994:53:134-41.

Faust M, Altenburger R, Backhaus T, Bodeker W, Scholze M, Grimme LH. Predictive assessment of the aquatic toxicity of multiple chemical mixtures. J Environ Qual 2000;29:1063-8.

Faust M, Altenburger R, Backhaus T, Blanck H, Boedeker W, Gramatica P, et al. Joint algal toxicity of 16 dissimilarly acting chemicals is predictable by the concept of independent action. Aquat Toxicol 2003;63:43-63.

Fuhrer GJ, Morace JL, Johnson HM, Rinella JF, Ebbert JC, Embrey SS, et al. Water quality in the Yakima River basin, Washington, 1999-2000. Circular. Reston, VA: U.S. Geological Survey; 20041237 [34 pp.].

Ganapathy C. Preliminary results of acute chronic toxicity testing of surface water monitored in the San Joaquin River watershed, winter 1997-1998. Memorandum from Carissa Ganapathy to Donald Weaver, January 5, 1999. Sacramento, CA: California Department of Pesticide Regulation; 1999a [27 pp.].

Ganapathy C. Preliminary results of acute chronic toxicity testing of surface water monitored in the San Joaquin River watershed, winter 1998-1999. Memorandum from Carissa Ganapathy to Donald Weaver, July 20, 1999. Sacramento, CA: California Department of Pesticide Regulation; 1999b [22 pp.].

GfK Kynetec. Unpublished proprietary agricultural pesticide use data for 2009, 2009

Gill S. Preliminary results of pesticide residue analysis and acute and chronic toxicity testing of surface water monitored in the Sacramento River watershed, winter 2000-2001 (study number 199). Memorandum from Sheryl Gill to Kean Goh, January 22, 2002. Sacramento, CA: California Department of Pesticide Regulation; 2002 [25 pp.].

Gilliom RJ, Barbash JE, Crawford CG, Hamilton PA, Martin JD, Nakagaki N, et al. The quality of our Nation's waters-pesticides in the Nation's streams and ground water, 1992-2001. Circular. Reston, VA: U.S. Geological Survey; 20061291 [172 pp.].

Guy M, Singh L, Mineau P. Using field data to assess the effects of pesticides on crustacea in freshwater aquatic ecosystems and verifying the level of protection provided by water quality guidelines. Integr Environ Assess Manag 2011;7:426-36.

Helsel DR, Hirsch RM. Statistical methods in water resources. New York: Elsevier Science; 1992.

Ingersoll C, MacDonald D, Wang N, Crane J, Field L, Haverland P, et al. Predictions of sediment toxicity using consensus-based freshwater sediment quality guidelines. Arch Environ Contam Toxicol 2001;41:8-21.

Jonczyk E, Gilron G. Acute and chronic toxicity testing with Daphnia sp. In: Blaise C, Férard J-F, editors. Small-scale Freshwater Toxicity Testing for freshwater Environments. Small-scale Freshwater Toxicity Investigations. Toxicity Test MethodsSpringer; 2005. p. 337-93.

Jones D. Preliminary results of acute and chronic toxicity testing of surface water monitored in the San Joaquin River watershed, winter 1999-2000. Memorandum from 
DeeAn Jones to Patricia Dunn, October 3, 2000. Sacramento, CA: California Department of Pesticide Regulation; 2000 [23 pp.].

Junghans M, Backhaus T, Faust M, Scholze M, Grimme LH. Application and validation of approaches for the predictive hazard assessment of realistic pesticide mixtures. Aquat Toxicol 2006;76:93-110.

Kim D, Walters J, Sava R. Preliminary background results of organophosphate analysis and acute toxicity testing of surface water monitored for the red imported fire ant project in Orange County, March and April, 1999. Memorandum from Dave Kim, Johanna Walters, and Roger Sava to Kean S Goh, November 29, 1999. Sacramento, CA: California Department of Pesticide Regulation; 1999a [7 pp.].

Kim D, Walters J, Sava R. Preliminary results of pesticide analysis and acute toxicity testing of monthly surface water monitoring for the red imported fire ant project in Orange County, May and June, 1999. Memorandum from Dave Kim, Johanna Walters, and Roger Sava to Kean S Goh, December 2, 1999. Sacramento, CA: California Department of Pesticide Regulation; 1999b [8 pp.].

Kimerle R, Barnthouse L, Brown R, de Beyssac BC, Gilbertson M, Monk K, et al. Ecological effects, Chap. 4 in Chemical ranking and scoring-guidelines for relative assessments of chemicals. In: Swanson MB, Socha AC, editors. Proceedings of the Pellston Workshop on Chemical Ranking and Scoring, 12-16 February, 1995, Sandestin, FL. SETAC special publication seriesPensacola, FL: SETAC Press; 1997. p. 89-111.

Kuivila KM, Foe CG. Concentrations, transport and biological effects of dormant spray pesticides in the San Francisco Estuary, California. Environ Toxicol Chem 1995:14:1141-50.

Liess M, von der Ohe PC. Analyzing effects of pesticides on invertebrate communities in streams. Environ Toxicol Chem 2005;24:954-65.

Lydy M, Belden J, Wheelock C, Hammock B, Denton D. Challenges in regulating pesticide mixtures. Ecol Soc 2004;9:1. [online, http://www.ecologyandsociety.org/vol9/iss6/ art1/].

MacDonald DD, Ingersoll CG, Berger TA. Development and evaluation of consensus-based sediment quality guidelines for freshwater ecosystems. Arch Environ Contam Toxicol 2000;39:20-31.

Maltby L, Blake N, Brock TCM, van den Brink PJ. Insecticide species sensitivity distributions: importance of test species selection and relevance to aquatic ecosystems. Environ Toxicol Chem 2005;24:379-88.

Maltby L, Brock TCM, van den Brink PJ. Fungicide risk assessment for aquatic ecosystems: importance of interspecific variation, toxic mode of action, and exposure regime. Environ Sci Technol 2009:43:7556-63.

Munn MD, Gilliom RJ. Pesticide Toxicity Index for freshwater aquatic organisms. Water-Resources Investigations Report 01-4077. Reston, VA: U.S. Geological Survey; 2001. [55 pp.].

Munn MD, Gilliom RJ, Moran PW, Nowell LH. Pesticide Toxicity Index for freshwater aquatic organisms. Scientific Investigations Report 2006-5148. 2nd ed. Reston, VA: U.S. Geological Survey; 2006. [81 pp.].

Nordmark C. Preliminary results of acute and chronic toxicity testing of surface water monitored in the Sacramento River watershed, winter 1998-1999. Memorandum from Craig Nordmark to Don Weaver, May 26, 1999. Sacramento, CA: California Department of Pesticide Regulation; 1999 [32 pp.].

Nordmark C. Preliminary results of acute and chronic toxicity testing of surface water monitored in the Sacramento River watershed, winter 1999-2000. Memorandum from Craig Nordmark to Don Weaver, September 15, 2000. Sacramento, CA: California Department of Pesticide Regulation; 2000 [29 pp.].

Norman JE, Kuivila KM, Nowell LH. Prioritizing pesticide compounds for analytical methods development. Scientific Investigations Report 2012-5045. Reston, VA: U.S. Geological Survey; 2012. [206 pp.].

Organization for Economic Cooperation and Development. Test No. 202: Daphnia sp. Acute immobilisation test, OECD guidelines for testing of chemicals, Section 2. OECD; 2004 [12 pp.].

Persoone G, Baudo R, Cotman M, Blaise C. Thompson KC, Moreira-Santos M, et al. Review on the acute Daphnia magna toxicity test - evaluation of the sensitivity and the precision of assays performed with organisms from laboratory cultures or hatched from dormant eggs. Knowl Manag Aquat Ecosyst 2009;393:29.

Phillips BM, Anderson BS, Hunt JW, Siegler K, Voorhees JP, Tjeerdema RS, et al. Pyrethroid and organophosphate pesticide-associated toxicity in two coastal watersheds (California, USA). Environ Toxicol Chem 2012;31:1595-603.

Posthuma L, de Zwart D. Predicted effects of toxicant mixtures are confirmed by changes in fish species assemblages in Ohio, USA, rivers. Environ Toxicol Chem 2006;25: 1094-105.

Posthuma L, de Zwart D. Predicted mixture toxic pressure relates to observed fraction of benthic macrofauna species impacted by contaminant mixtures. Environ Toxicol Chem 2012;31:2175-88.

Ryberg KR, Vecchia AV, Martin JD, Gilliom RJ. Trends in pesticide concentrations in urban streams in the United States, 1992-2008. Scientific Investigations Report 2010-5139 2010-5139. Reston, VA: U.S. Geological Survey; 2010. [101 pp.].

Sala S, Migliorati S, Monti GS, Vighi M. SSD-based rating system for the classification of pesticide risk on biodiversity. Ecotoxicology 2012:21:1050-62

Schäfer RB, Pettigrove V, Rose G, Allinson G, Wightwick A, von der Ohe PC, et al. Effects of pesticides monitored with three sampling methods in 24 sites on macroinvertebrates and microorganisms. Environ Sci Technol 2011a;45:1665-72.

Schäfer RB, von der Ohe PC, Kühne R, Schüürmann G, Liess M. Occurrence and toxicity of 331 organic pollutants in large rivers of north Germany over a decade (1994 to 2004). Environ Sci Technol 2011b;45:6167-74.

Schäfer RB, von der Ohe PC, Rasmussen J, Kefford BJ, Beketov MA, Schulz R, et al. Thresholds for the effects of pesticides on invertebrate communities and leaf breakdown in stream ecosystems. Environ Sci Technol 2012;45:5134-42.

Schäfer RB, Gerner N, Kefford BJ, Rasmussen JJ, Beketov MA, de Zwart D, et al. How to characterize chemical exposure to predict ecologic effects on aquatic communities? Environ Sci Technol 2013;47:7996-8004.
Sprague JB, Ramsay BA. Lethal levels of mixed copper-zinc solutions for juvenile salmon. J Fish Res Board Can 1965;22:425-32.

Stenström JR. Mixture toxicity of pesticides and biological effects in agricultural streams. LicentiateUppsala, Sweden: Faculty of Natural Resources and Agricultural Sciences, Department of Aquatic Sciences and Assessment, Swedish University of Agricultural Sciences; 201343.

Stephan CE, Mount DI, Hanson DJ, Gentile JH, Chapman GA, Brungs WA. Guidelines for deriving numerical National Water Quality Criteria for the protection of aquatic organisms and their uses. EPA PB85-227049. Duluth, MN: U.S. Environmental Protection Agency, Environmental Research Laboratories; 1985.

Sullivan DJ, Vecchia AV, Lorenz DL, Gilliom RJ, Martin JD. Trends in pesticide concentrations in corn-belt streams, 1996-2006. Scientific Investigations Report 2009-5132. Reston, VA: U.S. Geological Survey; 2009. [75 pp.].

Tate CM, Heiny JS. The ordination of benthic invertebrate communities in the South Platte River Basin in relation to environmental factors. Freshw Biol 1995;33:439-54.

TIBCO Software Inc.. TIBCO Spotfire S + 8.1 for Windows, Revision Date 11/4/2008; 2008.

University of Hertfordshire. The Pesticide Properties DataBase (PPDB) developed by the Agriculture \& Environment Research Unit (AERU) at the University of Hertfordshire, 2006-2013. Accessed September-October, 2012, and May 2013, at http://sitem.herts.ac.uk/aeru/ppdb/en/index.htm.

U.S. Environmental Protection Agency. Ecological effects test guidelines. OPPTS 850.1010 aquatic invertebrate acute toxicity test, freshwater daphnids, public draft. EPA 712-C-96-114. Washington, DC: U.S. Environmental Protection Agency, Office of Prevention, Pesticides and Toxic Substances; 1996 [10 pp.].

U.S. Environmental Protection Agency. Chlorpyrifos revised risk assessment and agreement with registrants. Fact sheet. Washington, DC: U.S. Environmental Protection Agency, Prevention, Pesticides and Toxic Substances; 2000 [4 pp.].

U.S. Environmental Protection Agency. Diazinon revised risk assessment and agreement with registrants. Fact sheet. Washington, DC: U.S. Environmental Protection Agency, Prevention, Pesticides and Toxic Substances; 2001 [4 pp.].

U.S. Environmental Protection Agency. Methods for measuring the acute toxicity of effluents and receiving waters to freshwater and marine organisms. EPA 821-R-02-0125th ed. Washington, DC: U.S. Environmental Protection Agency, Office of Water; 2002 [266 pp.].

U.S. Environmental Protection Agency. Wadeable streams assessment - a collaborative survey of the Nations's streams. EPA 841-B-06-002. Washington, DC: U.S. Environmental Protection Agency, Office of Research and Development, Office of Water; 2006 [113 pp.].

U.S. Environmental Protection Agency. ECOTOX user guide: ECOTOXicology Database System, Version 4.0. Duluth, MN: U.S. Environmental Protection Agency, Office of Research and Development and the National Health and Environmental Effects Research Laboratory's Mid-Continent Ecology Division; 2011 [96 pp.].

U.S. Environmental Protection Agency. ECOTOXicology Database System, Version 4.0. U.S Environmental Protection Agency, Office of Research and Development and the National Health and Environmental Effects Research Laboratory's Mid-Continent Ecology Division; 2012a [Updated June 15, 2012, Accessed July 5, 2012, at http:// www.epa.gov/ecotox/]

U.S. Environmental Protection Agency. Office of Pesticide Programs' aquatic life benchmarks (freshwater). U.S. Environmental Protection Agency, Office of Pesticide Programs; 2012b [Updated May 30, 2102, Accessed September-October, 2012 at http://www.epa.gov/oppefed1/ecorisk_ders/aquatic_life_benchmark.htm].

van den Brink PJ, Blake N, Brock TCM, Maltby L. Predictive value of species sensitivity distributions for effects of herbicides in freshwater ecosystems. Hum Ecol Risk Assess 2006; 12:645-74

Waite IR, Sobieszcyk S, Carpenter KD, Arnsberg AJ, Johnson HM, Hughes CA, et al. Effects of urbanization on stream ecosystems in the Willamette River basin and surrounding area, Oregon and Washington. Scientific Investigations Report 2006-5101-D. Reston, VA: U.S. Geological Survey; 2006. [63 pp.].

Walters J. Kim D, Goh KS. Preliminary results of pesticide analysis and acute toxicity testing of monthly surface water monitoring for the red imported fire ant project in Orange County, August 2000 (Study 183). Memorandum from Johana Walters, Dave Kim, and Kean S. Goh to John S. Sanders, October 5, 2000. Sacramento, CA: California Department of Pesticide Regulation; 2000a [10 pp.]

Walters J, Kim D, Goh KS. Preliminary results of pesticide analysis and acute toxicity testing of monthly surface water monitoring for the red imported fire ant project in Orange County, July 2000 (Study 183). Memorandum from Johana Walters, Dave Kim, and Kean S. Goh to John S. Sanders, October 5, 2000. Sacramento, CA: California Department of Pesticide Regulation; 2000b [10 pp.].

Walters J, Kim D, Goh KS. Preliminary results of pesticide analysis and acute toxicity testing of monthly surface water monitoring for the red imported fire ant project in Orange County, June 2000 (Study 183). Memorandum from Johana Walters, Dave Kim, and Kean S. Goh to John S. Sanders, September 1, 2000. Sacramento, CA: California Department of Pesticide Regulation; 2000c [9 pp.].

Walters J, Kim D, Goh KS. Preliminary results of pesticide analysis and acute toxicity testing of monthly surface water monitoring for the red imported fire ant project in Orange County, September 2000 (Study 183). Memorandum from Johana Walters, Dave Kim, and Kean S. Goh to John S. Sanders, December 22, 2000. Sacramento, CA: California Department of Pesticide Regulation; 2000d [12 pp.].

Walters J, Kim D, Sava R, Goh KS. Preliminary results of pesticide analysis and acute toxicity testing of monthly surface water monitoring for the red imported fire ant project in Orange County, April 2000 (Study 183). Memorandum from Johan Walters, Dave Kim, Roger Sava, and Kean S. Goh to John S. Sanders, July 6, 2000 Sacramento, CA: California Department of Pesticide Regulation; 2000e [10 pp.].

Walters J, Kim D, Sava R, Goh KS. Preliminary results of pesticide analysis and acute toxicity testing of monthly surface water monitoring for the red imported fire ant project 
in Orange County, December 1999 (Study 183). Memorandum from Johana Walters, Dave Kim, Roger Sava, and Kean S. Goh to John S. Sanders, April 12, 2000. Sacramento, CA: California Department of Pesticide Regulation; 2000f [8 pp.].

Walters J, Kim D, Sava R, Goh KS. Preliminary results of pesticide analysis and acute toxicity testing of monthly surface water monitoring for the red imported fire ant project in Orange County, February 2000 (Study 183). Memorandum from Johana Walters, Dave Kim, Roger Sava, and Kean S. Goh to John S. Sanders, May 17, 2000. Sacramento, CA: California Department of Pesticide Regulation; 2000g [9 pp.].

Walters J, Kim D, Sava R, Goh KS. Preliminary results of pesticide analysis and acute toxicity testing of monthly surface water monitoring for the red imported fire ant project in Orange County, January 2000 (Study 183). Memorandum from Johana Walters, Dave Kim, Roger Sava, and Kean S. Goh to John S. Sanders, April 7, 2000. Sacramento, CA: California Department of Pesticide Regulation; 2000h [8 pp.].

Walters J, Kim D, Sava R, Goh KS. Preliminary results of pesticide analysis and acute toxicity testing of monthly surface water monitoring for the red imported fire ant project in Orange County, March 2000 (Study 183). Memorandum from Johana Walters, Dave Kim, Roger Sava, and Kean S. Goh to John S. Sanders, July 5, 2000. Sacramento, CA: California Department of Pesticide Regulation; 2000i [10 pp.]

Walters J, Kim D, Sava R, Goh KS. Preliminary results of pesticide analysis and acute toxicity testing of monthly surface water monitoring for the red imported fire ant project in Orange County, October 1999 (Study 183). Memorandum from Johana Walters, Dave Kim, Roger Sava, and Kean S. Goh to John S. Sanders, February 4, 2000. Sacramento, CA: California Department of Pesticide Regulation; 2000j [8 pp.].

Walters J, Kim D, Sava R, Goh KS. Preliminary results of pesticide analysis and acute toxicity testing of monthly surface water monitoring for the red imported fire ant project in Orange County, September 1999 (Study 183). Memorandum from Johana Walters, Dave Kim, Roger Sava, and Kean S. Goh to John S. Sanders, January 31, 2000. Sacramento, CA: California Department of Pesticide Regulation; 2000k [8 pp.]

Walters J, Kim D, Sava R, Goh KS. Results of pesticide analysis and acute toxicity testing of rain runoff monitoring for the red imported fire ant project in Orange County, January 2000 (Study 183). Memorandum from Johana Walters, Dave Kim, Roger Sava, and Kean S. Goh to John S. Sanders, May 30, 2000. Sacramento, CA: California Department of Pesticide Regulation; 20001 [10 pp.].

Walters J, Kim D, Sava R, Goh KS. Revised-preliminary results of pesticide analysis and acute toxicity testing of monthly surface water monitoring for the red imported fire ant project in Orange County, May 2000 (Study 183). Memorandum from Johana Walters, Dave Kim, Roger Sava, and Kean S. Goh to John S. Sanders, September 29, 2000. Sacramento, CA: California Department of Pesticide Regulation; 2000m [9 pp.].

Walters J, Kim D, Goh KS. Preliminary results of pesticide analysis and acute toxicity testing of monthly surface water monitoring for the red imported fire ant project in Orange County, August 2001 (Study 183). Memorandum from Johana Walters, Dave Kim, and Kean S. Goh to John S. Sanders, November 8, 2001. Sacramento, CA California Department of Pesticide Regulation; 2001a [11 pp.]

Walters J, Kim D, Goh KS. Preliminary results of pesticide analysis and acute toxicity testing of monthly surface water monitoring for the red imported fire ant project in Orange County, December 2000 (Study 183). Memorandum from Johana Walters, Dave Kim, and Kean S. Goh to John S. Sanders, April 26, 2001. Sacramento, CA: California Department of Pesticide Regulation; 2001b [10 pp.].

Walters J, Kim D, Goh KS. Preliminary results of pesticide analysis and acute toxicity testing of monthly surface water monitoring for the red imported fire ant project in Orange County, February 2001 (Study 183). Memorandum from Johana Walters,
Dave Kim, and Kean S. Goh to John S. Sanders, May 3, 2001. Sacramento, CA: California Department of Pesticide Regulation; 2001c [9 pp.].

Walters J, Kim D, Goh KS. Preliminary results of pesticide analysis and acute toxicity testing of monthly surface water monitoring for the red imported fire ant project in Orange County, January 2001 (Study 183). Memorandum from Johana Walters, Dave Kim, and Kean S. Goh to John S. Sanders, April 27, 2001. Sacramento, CA: California Department of Pesticide Regulation; 2001d [10 pp.].

Walters J, Kim D, Goh KS. Preliminary results of pesticide analysis and acute toxicity testing of monthly surface water monitoring for the red imported fire ant project in Orange County, July 2001 (Study 183). Memorandum from Johana Walters, Dave Kim, and Kean S. Goh to John S. Sanders, November 1, 2001. Sacramento, CA: California Department of Pesticide Regulation; 2001e [9 pp.].

Walters J, Kim D, Goh KS. Preliminary results of pesticide analysis and acute toxicity testing of monthly surface water monitoring for the red imported fire ant project in Orange County, June 2001 (Study 183). Memorandum from Johana Walters, Dave Kim, and Kean S. Goh to John S. Sanders, September 7, 2001. Sacramento, CA: California Department of Pesticide Regulation; 2001f [10 pp.].

Walters J, Kim D, Goh KS. Preliminary results of pesticide analysis and acute toxicity testing of monthly surface water monitoring for the red imported fire ant project in Orange County, March 2001 (Study 183). Memorandum from Johana Walters, Dave Kim, and Kean S. Goh to John S. Sanders, July 13, 2001. Sacramento, CA: California Department of Pesticide Regulation; 2001g [10 pp.].

Walters J, Kim D, Goh KS. Preliminary results of pesticide analysis and acute toxicity testing of monthly surface water monitoring for the red imported fire ant project in Orange County, May 2001 (Study 183). Memorandum from Johana Walters, Dave Kim, and Kean S. Goh to John S. Sanders, July 17, 2001. Sacramento, CA: California Department of Pesticide Regulation; 2001h [9 pp.].

Walters J, Kim D, Goh KS. Preliminary results of pesticide analysis and acute toxicity testing of monthly surface water monitoring for the red imported fire ant project in Orange County, November 2000 (Study 183). Memorandum from Johana Walters, Dave Kim, and Kean S. Goh to John S. Sanders, February 6, 2001. Sacramento, CA: California Department of Pesticide Regulation; 2001i [10 pp.].

Walters J, Kim D, Goh KS. Revised preliminary results of pesticide analysis and acute toxicity testing of monthly surface water monitoring for the red imported fire ant project in Orange County, April 2001 (Study 183). Memorandum from Johana Walters, Dave Kim, and Kean S. Goh to John S. Sanders, September 7, 2001. Sacramento, CA: California Department of Pesticide Regulation; 2001j [8 pp.]

Warne $\mathrm{M}$. A review of the ecotoxicity of mixtures, approaches to, and recommendations for, their management. In: Langgley A, Gilbey B, Kennedy B, editors. Proceedings of the Fifth National Workshop on the Assessment of Site Contamination. Adelaide, Australia: National Environment Protection Council Service Corp.; 2003.

Warne M, Hawker D. The number of components in a mixture determines whether synergistic and antagonistic or additive toxicity predominate: the funnel hypothesis. Ecotoxicol Environ Saf 1995;31:23-8.

Whiteside M, Mineau P, Morrison C, Knopper LD. Comparison of a score-based approach with risk-based ranking of in-use agricultural pesticides in Canada to aquatic receptors. Integr Environ Assess Manag 2008;4:215-36.

Yuan LL, Hawkins CP, Van Sickle J. Effects of regionalization decisions on an O/E index for the US national assessment. J N Am Benthol Soc 2008;27:892-905.

Yuan LL, Pollard AI, Carlisle DM. Using propensity scores to estimate the effects of insecticides on stream invertebrates from observational data. Environ Toxicol Chem 2009;28:1518-27. 
Pesticide Toxicity Index —A Tool for Assessing Potential Toxicity of Pesticide Mixtures to Freshwater Aquatic Organisms

Nowell, L.H., Norman, J.E., Moran, P.W., Martin, J.D., and Stone, W.W.

\section{Supplementary Information}

Appendix A. Supplementary methods

Appendix B. Summary of toxicity information for fish, cladocerans, and benthic invertebrates. This is a downloadable Excel file listing MTC and STC values for pesticides and degradates, for use in computing PTI values for field samples (Tables B.1-B.3).

Appendix C. Summary of taxa included in standard and non-standard bioassay data sets for pesticides and degradates and the number of bioassays and compounds per taxon. This is a downloadable Excel file (Tables C.1-C.2).

Appendix D. Pesticide concentrations and Ceriodaphnia dubia survival from published studies used to evaluate the PTI. This is a downloadable Excel file (Table D.1). 
Appendix A. Supplementary Methods

\section{Background information on toxicity data sources}

\subsection{ECOTOX database}

Toxicity data for each compound were obtained by searching U.S. Environmental Protection Agency's (USEPA's) ECOTOXicology (ECOTOX) Database, which was created and is maintained by the USEPA Office of Research and Development and the USEPA National Health and Environmental Effects Research Laboratory's (NHEERL) Mid-Continent Ecology Division (U.S. Environmental Protection Agency, 2012a), and is updated approximately quarterly. This database contains several previously separate data sets, including USEPA's AQUIRE Database (which was developed by the USEPA's NHEERL), the Pesticide Ecotoxicity Database (which was developed by the USEPA Office of Pesticide Programs (OPP), and two terrestrial databases, TERRETOX (for terrestrial animals) and PHYTOTOX (for terrestrial plants). The current ECOTOX database allows convenient searching through a single interface for multiple USEPA data sets. The ECOTOX database contains a wide range of toxicological data that are variable in nature and quality. Criteria were established by USEPA to ensure that the data were relatively comparable, but test conditions among studies vary. Factors that may contribute to variability include differences between test species, age and condition of test organisms, testing environment (e.g., static, flow through, renewal), water conditions (e.g., pH, temperature, dissolved organic carbon), and pesticide material being tested (technical grade active ingredient vs. formulations expressed on an active ingredient basis).

\subsection{Office of Pesticide Programs’ (OPP) aquatic life benchmarks}

A primary source of toxicity values for pesticides that did not have standardized test data from ECOTOX consisted of USEPA pesticide registration and risk assessment documents cited in USEPA OPP's table of aquatic-life benchmarks (U.S. Environmental Protection Agency, 2012b). These OPP benchmarks were derived on the basis of aquatic toxicity values reviewed by USEPA and used in USEPA's most recent risk assessments developed as part of the decision-making process for pesticide registration. OPP benchmarks include acute and chronic benchmarks for fish and invertebrates and acute benchmarks for vascular and nonvascular plants, but only the acute benchmarks for fish and invertebrates are relevant here because the scope of the Pesticide Toxicity Index (PTI) is restricted to acute toxicity to fish, cladocerans, and benthic invertebrates. For each pesticide with OPP benchmarks (U.S. Environmental Protection Agency, 2012b) USEPA typically cites the source document (e.g. a risk assessment) that contains the toxicity values upon which the benchmarks are based for that pesticide. OPP benchmarks typically are based on the most sensitive test result available from standardized toxicity tests judged by OPP to be acceptable or supplemental. The USEPA source documents for some pesticides listed only 
the toxicity value that corresponds to the benchmark (i.e., the most sensitive value), whereas source documents for other pesticides listed toxicity values from additional suitable tests available at that time. Some OPP benchmark values are unbounded-that is, reported as "greater than" or "less than" a specified concentration-because the EC50 or LC50 was greater than the highest concentration tested or less than the lowest concentration tested, respectively.

\subsection{Pesticide Properties Database}

The Pesticide Properties Database (PPDB) (University of Hertfordshire, 2013) was developed by the Agriculture and Environment Research Unit (AERU) based at the University of Hertfordshire, UK. Ecological toxicity values in the PPDB are experimental values that include three categories: 96-hr LC50 values for fish, 48-hr EC50 values for aquatic invertebrates, and 96hr LC50 values for sediment-dwelling organisms (i.e., benthic invertebrates). A single toxicity value is listed for each category according to a species preference in the PPDB (University of Hertfordshire, 2013), unless data were not available for that category. The preferred species for fish are rainbow trout (Oncorhyncus mykiss), bluegill (Lepomis macrochirus), and zebra fish (Brachydanio rerio). For aquatic invertebrates, the preferred species are daphnids (Daphnia magna or D. pulex). For sediment dwelling organisms, the preferred species is midge (Chironomus riparius). Data from other species may be included in the PPDB if data for preferred species are not available. Where data are available for multiple species, the most sensitive toxicity value is provided. Data in the PPDB are graded by the AERU from 1 (low) to 5 (high) according to the degree of confidence in the data. A low score does not necessarily indicate incorrect data but indicates that the AERU was not able to verify the value.

\section{Inclusion of EC50 (immobilization) and LC50 values as cladoceran endpoints}

Toxicity data for cladocerans included both EC50 with immobilization as the endpoint and LC50 values to determine toxicity concentrations. It is difficult to ascertain organism mortality with certainty without examining the organism under a dissecting microscope for a heartbeat. Determination of mortality is especially difficult for narcotic chemicals, which may slow the heartbeat to 1 to 2 beats per minute (Jonczyk and Gilron, 2005). Immobilization is a widely accepted alternative endpoint, and is typically is defined as the inability of the test organisms to resume swimming within 15 seconds after gentle agitation. Both endpoints are widely used and have standardized methods available: immobilization (Commission of the European Communities, 1992; Organization for Economic Cooperation and Development, 2004; U.S. Environmental Protection Agency, 1996) and mortality (U.S. Environmental Protection Agency, 2002). Extensive databases on acute effects of chemicals on daphnids show that LC50 and EC50 values do not differ markedly (Persoone et al., 2009). This was largely confirmed in the present study by evaluating paired 48-hour EC50 and LC50 values from the ECOTOX database, with each pair measured for the same pesticide during a single study. Of 940 cladoceran bioassays, there were only 18 pairs of EC50 and LC50 values for 6 pesticides total. Paired EC50 and LC50 
values were highly correlated (Spearman rho of 0.979), and the EC50 values for immobilization were significantly lower than the paired LC50 values ( $\mathrm{p}<0.0001$, Wilcoxon signed rank test). However, the LC50 value was within a factor of 2 of the EC50 value for 5 of the 6 compounds, and for 16 of the 18 pairs. The exception was imidacloprid in two studies, for which the EC50 for immobilization was 4- and 20-times lower than the LC50.

\section{Procedure for determining sensitive toxicity concentration (STC) values}

We considered five approaches for determining the STC, which is the basis of the Sensitive-PTI. Ultimately we tested approaches B, D, and E, calculating STCs using all three methods.

A. Use the minimum toxicity value for a given compound as the STC. This follows USEPA OPP's procedure for ecological assessment and development of OPP aquatic-life benchmarks, except that USEPA applies an additional safety factor. This would give us the most sensitive STC, which is acceptable for a screening tool. However, variability among tests for a given pesticide and species can be high, and to the extent possible, we want to avoid selecting a statistical outlier as the STC. By this approach, as future test data are added to the database, the addition of one new low toxicity value could alter the STC substantially. Because of susceptibility to outliers, we elected not to pursue this approach.

B. Use the $5^{\text {th }}$ percentile (unweighted) of toxicity tests when there are more than 12 test values; if there are 12 or fewer test values use the minimum. To the degree possible (limited by the scarcity of data), this approach would minimize the chance of selecting a statistical outlier as the STC. Based on Monte Carlo simulations described in Supplemental Information A.4, the probability is less than $50 \%$ that a sample of 12 or fewer tests would contain a low outlier (defined as within the bottom 5 percent of a theoretical population of toxicity tests results). For samples with more than 12 tests, we computed the $5^{\text {th }}$ percentile value because the probability is greater than $50 \%$ that a sample of more than 12 toxicity tests would contain a low outlier. Because tests are not weighted by species, this approach maximizes the sample size per compound. Because of the uneven nature of the toxicity test data, with some species tested more often than others, the use of unweighted toxicity values will result in certain (more frequently tested) species having more influence on the STC than rarely tested species. This will tend to bias the STC slightly low, because some of the most commonly tested species tend to be sensitive (e.g, lower species geometric means). This is illustrated in Figure A.1 for selected pesticides. We computed STC values using this approach, for evaluation. 


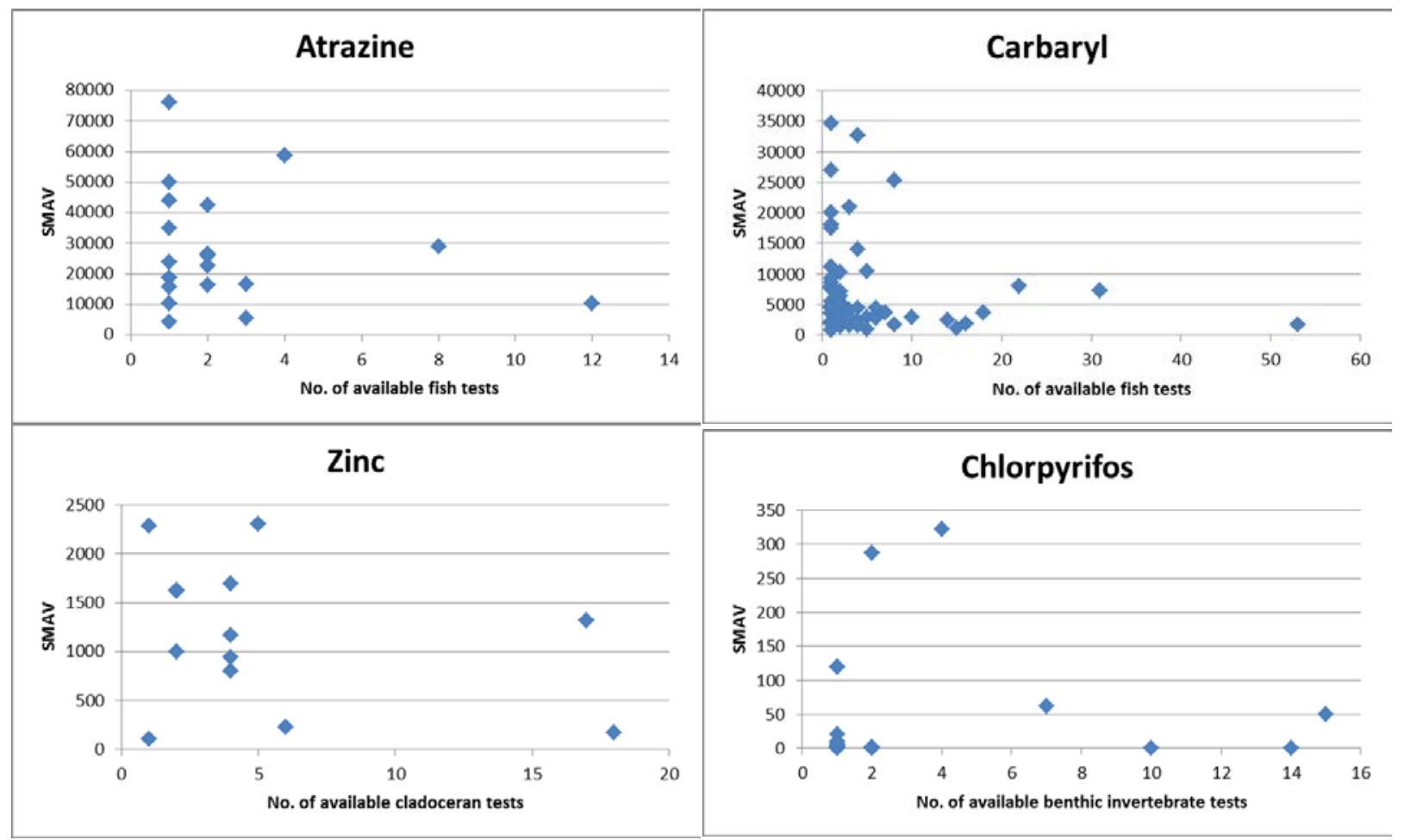

Fig. A1. Species with more toxicity tests tend to have relatively low Species Mean Acute Values (SMAV), compared to many species with fewer tests, as illustrated for (a) Atrazine tests with fish, (b) Carbaryl tests with fish, (c) Zinc tests with cladocerans, and (d) Chlorpyrifos tests with benthic invertebrates.

C. Determine Species Sensitivity Distribution (SSD) and take $5^{\text {th }}$ percentile hazardous concentration (HC5): We ruled out this approach because too many of our pesticide compounds had insufficient data to determine a SSD_for example, we have data for only $1-2$ species for $38 \%$ of compounds for fish, $86 \%$ for clads, and $38 \%$ for BI. Our objective is to use only experimental toxicity data, and to avoid introducing additional uncertainty due to data estimation and curve-fitting on the basis of few data points.

D. Aggregate toxicity data by species, determine the geometric mean as the Species Mean Acute Value (SMAV) for each compound/species combination, and then use the minimum SMAV as the STC for a compound. This approach follows USEPA Office of Water procedures for deriving SMAVs, which represents the geometric mean of toxicity tests available for a given compound and species. This approach weights species equally. Aggregating the available toxicity data by species reduced the sample size for most compounds because we usually have fewer species than we have tests. For certain compounds, because of the distribution of available toxicity data, we had more than 12 individual toxicity tests (so therefore we can compute a $5^{\text {th }}$ percentile of unweighted toxicity values using Approach B) but the minimum SMAV was associated with only one toxicity test. For these compounds, that single toxicity test would determine the speciesweighted STC. This occurred for $10 \%$ of pesticides for fish, $2 \%$ for cladocerans, and $10 \%$ for benthic invertebrates. By this approach, some tests have more influence than others 
on the STC. Furthermore, particularly for the cladoceran dataset, there are many examples of compounds that have only one species represented, but multiple tests for that species. In the cladoceran dataset, 118 compounds have data for only one species, but have 2 or more tests for that species. In these cases, by taking the minimum SMAV as the STC, the STC becomes the geometric mean of all tests for that compound-which in many cases is similar to, or even greater than, the median toxicity concentration (MTC) and not a particularly sensitive value for that compound. Using the species-weighted approach also makes it more likely that the future addition of a single new test result to the database of toxicity values could substantially alter an STC. We computed STC values using this approach, for evaluation.

E. Aggregate by species, determine the SMAVs for each compound/species combination, and then (if more than 12 species are represented) calculate the $5^{\text {th }}$ percentile of the SMAVs as the STC, or (if 12 or fewer species are represented) use the minimum SMAV as the STC. This approach weights species equally. This approach is more robust to outliers than taking the minimum toxicity value (Approach A) or the minimum SMAV (Approach D) because it follows the logic of the Monte Carlo simulations, which showed that the probability of a sample containing a low outlier is greater than $50 \%$ if the samples has 13 or more tests, but less than $50 \%$ if the sample has fewer than 13 tests. However, because toxicity data were limited, many pesticides (especially for cladocerans) had fewer than 13 species, so the STC was the minimum SMAV. This approach still resulted in a few low outliers, and overall, species-weighting raised the STC values for most compounds compared to Approach B. We computed STC values using this approach, for evaluation.

Although aggregating by species prior to determining the STC is preferable, in theory, the unevenness and scarcity of the available data created problems when STC values were based on SMAVs. This is illustrated in Figures A.2 and A.3, in which STC values from Approaches D and E (respectively) are plotted on the y-axis compared to unweighted STCs (Approach B) on the Xaxis. Each symbol represents a pesticide, and is color-coded according to the number of toxicity tests available for that pesticide. Pesticides with only 1 toxicity test available are excluded, and the 1:1 line is shown. The STC values calculated using all three approaches are strongly correlated with one another ( $\left.\mathrm{p}<0.001, \mathrm{R}^{2}>92 \%\right)$, although Figures A.2 and A.3 are log-scale, so values for individual pesticides located farthest from the 1:1 line may differ substantially between each pair of approaches. With some exceptions, taking the minimum SMAV tended to raise the value of the STC for most pesticides. The dark and light green symbols indicate pesticides with the largest number (3 or more) of tests performed with the species that has the lowest SMAV, so the confidence associated with these SMAVs is higher. Notably, red triangles indicate pesticides for which multiple tests were conducted, but the minimum SMAV corresponds to only 1 test; yellow triangles indicate pesticides for which the minimum SMAV was based on two tests. The orange and (especially) red triangles are potential outliers. Most of the low outliers located below the 1:1 line in Fig. A.2 (Approach D) disappeared when in Fig. 


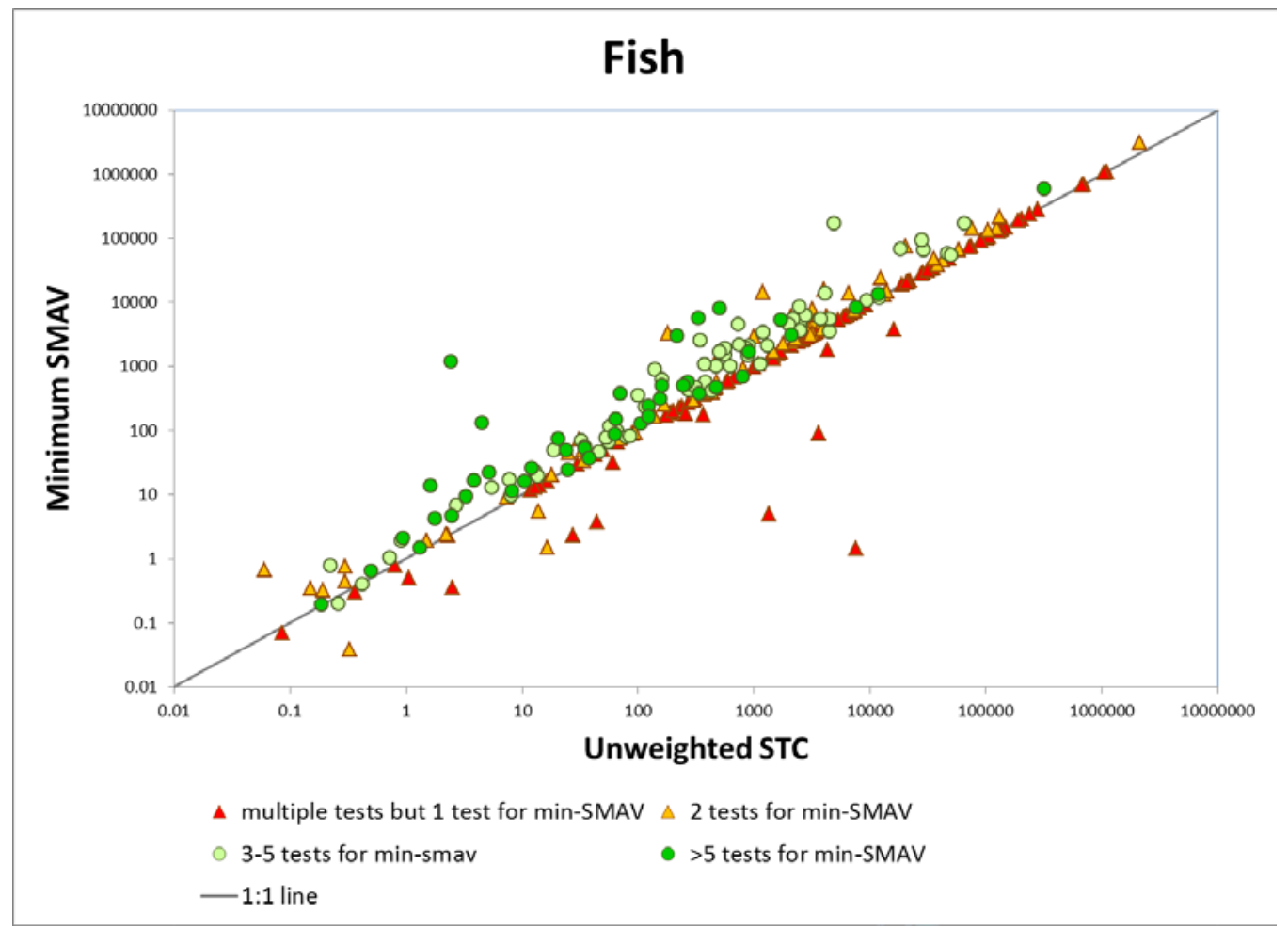

Fig. A.2. Comparison of the STC equal to the minimum SMAV (Approach D) vs. the unweighted STC (Approach B).

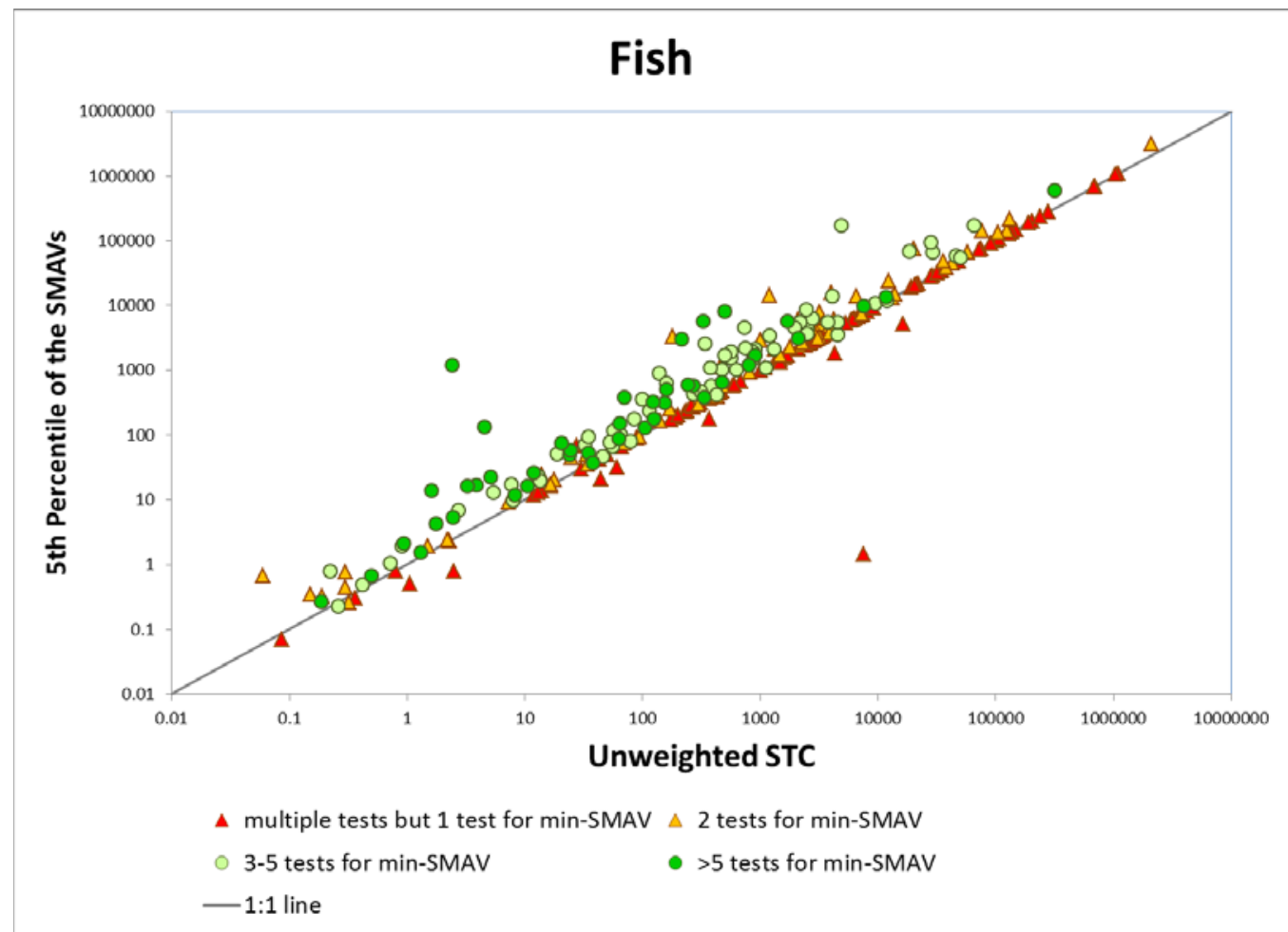

Fig. A.3. Comparison of the STC equal to the $5^{\text {th }}$ percentile SMAV (Approach E) vs. the unweighted STC (Approach B). 
A.3 (Approach E), because these pesticides had $>12$ species so we were able to compute the $5^{\text {th }}$ percentile of the SMAVs. One pesticide (the insecticide acephate) persists as an outlier in fish; its lowest SMAV is based on a single test with a toxicity value that is more than four orders of magnitude lower than the second lowest toxicity value.

Because of the limitations in the toxicity dataset, all three approaches $(\mathrm{B}, \mathrm{D}, \mathrm{E})$ are biased. Whereas Approach B gives some species more influence than others over the STC, Approaches $\mathrm{D}$ and $\mathrm{E}$ give some tests more influence than others over the STC. STC values computed using Approach B (unweighted) typically were lower than those computed using Approaches D or E, reflecting the fact that the many common test species tended to be fairly sensitive. The direction of bias from Approach B is acceptable for a screening tool designed to be a sensitive indicator of toxicity. In contrast, the bias from Approaches D and E was more unpredictable-for pesticides with multiple tests but only one species, the STC tended to be biased high, whereas for pesticides for which the lowest SMAV was based on a single species, the STC may be biased low. Because our objective was a simple, straight-forward tool based on experimental data, which will represent as many pesticides as possible and have minimal influence from statistical outliers, we elected to use Approach B to determine STC values.

\section{Calculation of 5 th percentile toxicity values for STC values}

Monte Carlo simulations were used to explore the effect of sample size on the likelihood that the minimum toxicity value for a given pesticide and taxonomic group would be a low statistical outlier-defined as less than the $5^{\text {th }}$ percentile of all hypothetical toxicity values. This was done to inform the process of determining STC values, using the rationale that, if the minimum toxicity value has a low probability (defined as $<50 \%$ ) of being a low statistical outlier, then the minimum toxicity value can be used as the STC, in lieu of the $5^{\text {th }}$ percentile. First, pesticides were identified that had $S \geq 20$, where $S$ is the number of available standard toxicity values for a given pesticide and taxonomic group. The set of $S \geq 20$ toxicity values for a given pesticide is referred to as the "sample" in the following discussion. For fish, 63 of the 296 pesticides with standard toxicity data had 20 or more values. For cladocerans and benthic invertebrates, 17 of 277 and 17 of 135 pesticides, respectively, had 20 or more toxicity values.

Next, for each pesticide with $S \geq 20$, a series of random subsamples of $n$ toxicity values, with $n$ varying between 2 and 20, were selected from the sample, and the minimum value of each subsample was compared to the sample $5^{\text {th }}$ percentile value for that pesticide and taxonomic group. This subsampling procedure was repeated 1,000 times for each value of $n$ for each pesticide within each taxonomic group. If a subsample minimum was below the sample $5^{\text {th }}$ percentile, it was by definition considered to be an extreme value. These simulations showed the effect of subsample size $(n)$ on the frequency at which the subsample minimum value was below 
the sample $5^{\text {th }}$ percentile for a given pesticide-i.e., the probability of the subsample containing one or more extreme values. Figure A.4 illustrates, for each pesticide with 20 or more fish bioassays ( $S \geq 20$ ), the percentage of simulations in which the subsample minimum was less than the sample $5^{\text {th }}$ percentile toxicity value for fish. Each curve in Figure A.4.a represents a different subsample size $n$, and for a given value of $n$, each symbol represents an individual pesticide. As shown in Figure A.4.a, as the subsample size $(n)$ approaches the sample size $(S)$ for a given pesticide, the probability that the subsample will contain extreme values (i.e., values below the $5^{\text {th }}$ percentile of the sample) becomes quite high and its relation to $S$ is non-linear. For example, random subsamples of $n=20$ contained one or more toxicity values below the $5^{\text {th }}$ percentile $80 \%$ of the time for pesticides with $S$ of $20-40$. When the plot was restricted to pesticides with $S \geq 5 * n$, as shown in Figure A.4.b, the percentage of simulations in which the subsample minimum was below the sample $5^{\text {th }}$ percentile was nearly constant (independent of $S$ ) and linear for a given value of $n$; moreover, this percentage increased as $n$ increased (Fig. A.4.b). 

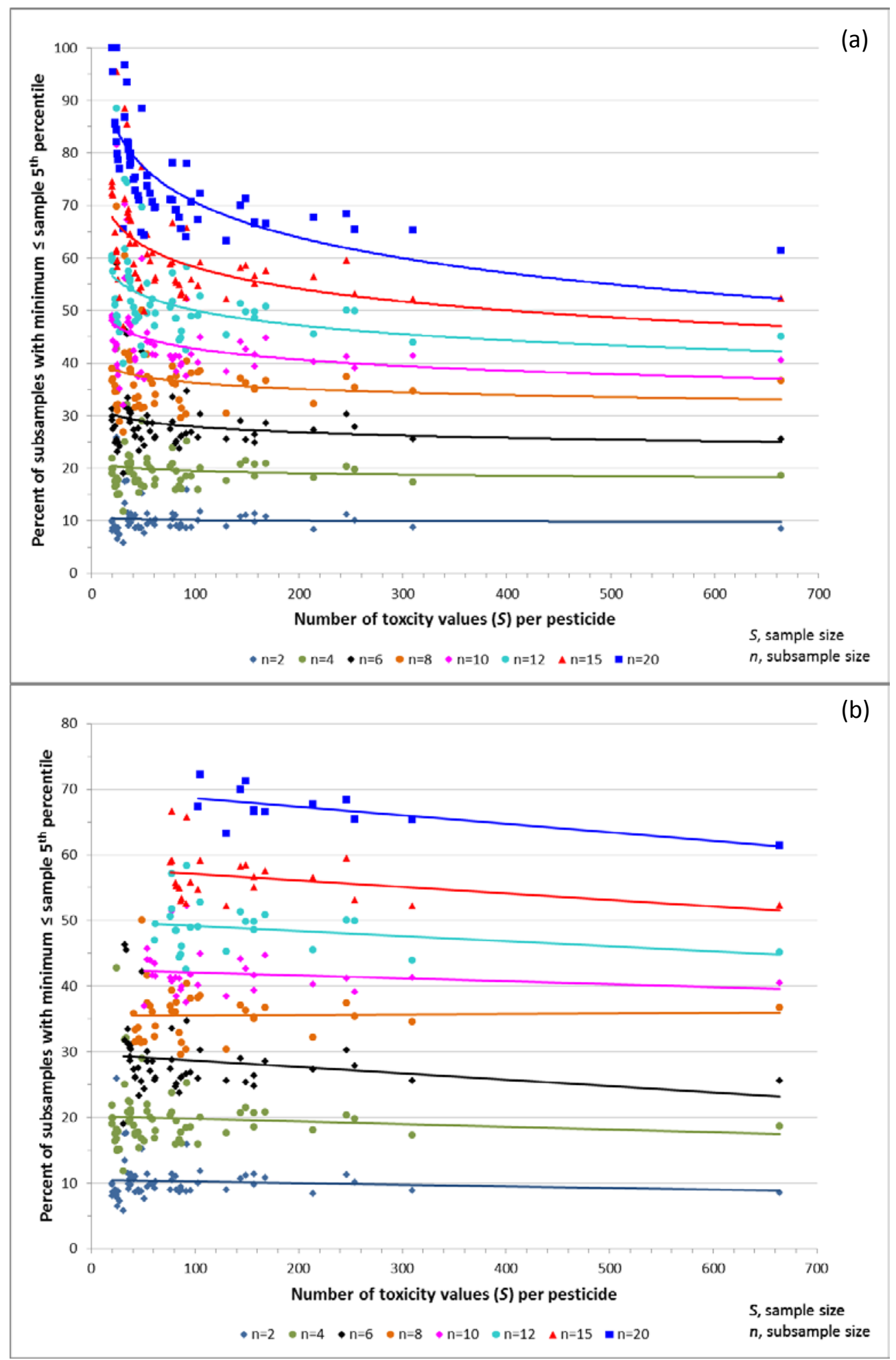

Fig. A.4. The percentage of simulations in which the subsample minimum value was $\leq$ the sample $5^{\text {th }}$ percentile, as a function of subsample size $(n)$, for all pesticides in the fish dataset with (a) at least 20 toxicity values and (b) $S \geq 5^{*} n$ and at least 20 toxicity values. The y-axis values represent the probability (i.e., the percentage of simulations) that the minimum value of the subsample is a low outlier. 
For each value of $n$, the probability values for all pesticides represented in Figure A.4.b were averaged and these average probability values were plotted vs. subsample size in Figure A.5. As illustrated for fish in Figure A.5, when $n$ was 12 or less, the subsample minimum value was $\leq$ the sample 5th percentile (i.e., an extreme value) less than $50 \%$ of the time. Conversely, when $n$ was greater than 12 , the probability was greater than $50 \%$ that the subsample minimum value was $\leq$ the sample $5^{\text {th }}$ percentile (an extreme value), and this probability increased as $n$ increased from 12 to 20 (Fig. B.2). This suggests that, for pesticides with 12 or fewer toxicity values available, the probability is $<50 \%$ that the minimum toxicity value would be in the lowest $5^{\text {th }}$ percentile of a hypothetical larger population of toxicity values; therefore, the minimum value was used as the STC for pesticides with $S \leq 12$ because it is unlikely to be a low statistical outlier. For pesticides with 13 or more toxicity values, the probability is greater than $50 \%$ that one or more of those values will be in the lowest $5^{\text {th }}$ percentile of a hypothetical larger population of toxicity values; therefore, the $5^{\text {th }}$ percentile of the available toxicity values was used as the STC.

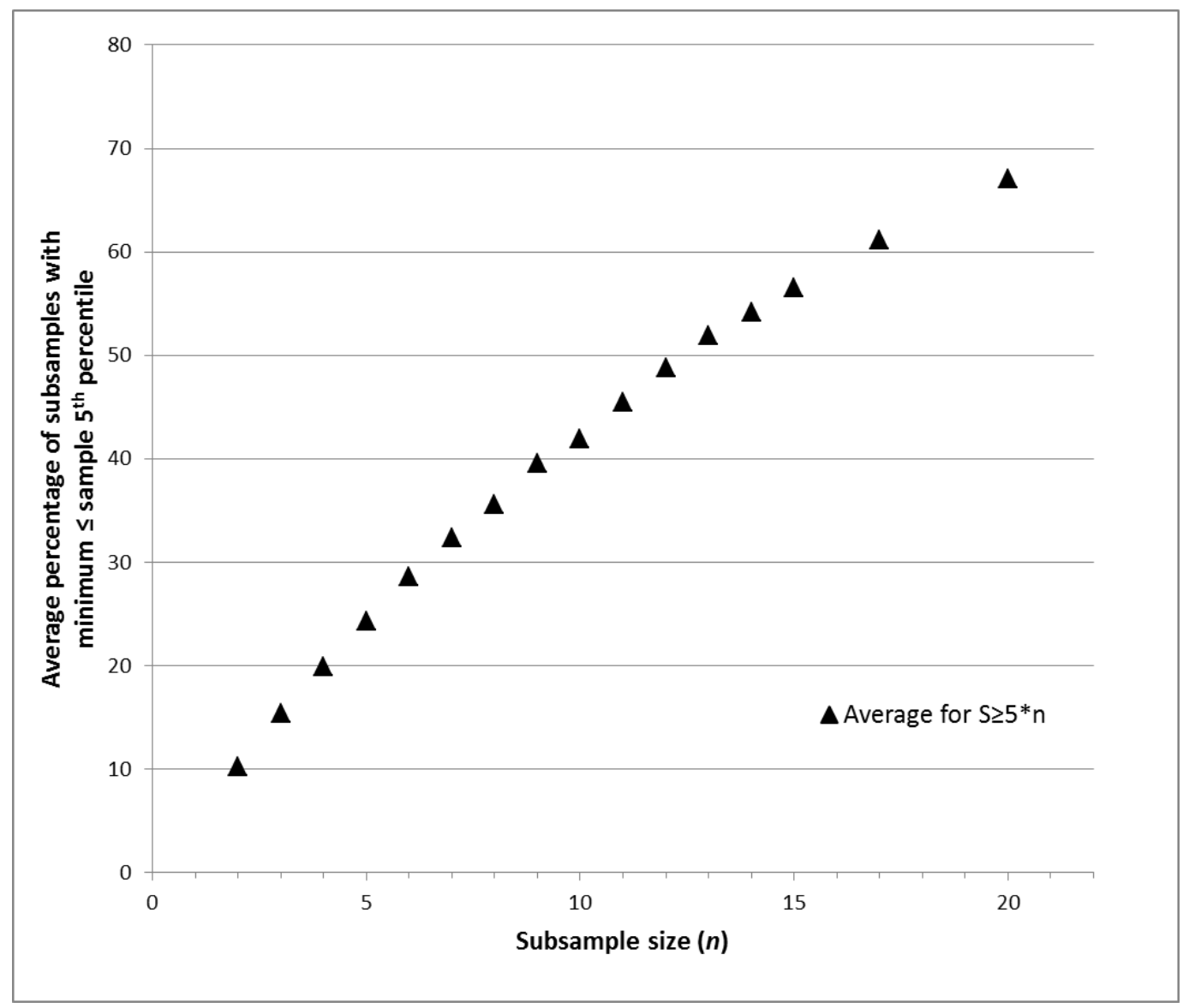

Fig. A.5. Average percentage of simulations in which the subsample minimum value was less than or equal to the sample $5^{\text {th }}$ percentile for pesticides in the fish dataset with $S$ toxicity tests available, as a function of subsample size $(n)$. Of the pesticides with $S \geq 20$, only those with $S \geq 5^{*} n$ values were included in the average computations. 
The subsample minimum was less than or equal to the 5th percentile was not substantially affected by removing the single pesticide with $S=664$ toxicity values, by further restricting the dataset to pesticides with $S \geq 100$ toxicity values, or by increasing the number of subsampling simulations to 10,000 or 20,000 . Furthermore, the results were comparable for cladocerans and benthic invertebrates, although there were far fewer pesticides with sufficient data for evaluation (both groups had 17 pesticides with $S \geq 20$ ) compared to fish (63 pesticides). These additional analyses (not shown graphically here) indicate that the Monte Carlo simulation procedure used to support the determination of STC values is fairly robust.

\section{References}

Commission of the European Communities. Commission Directive 92/69/EEC of 31 July 1992 adapting to technical progress for the 17th time Council Directive 67/548/EEC on the approximation of laws, regulations and administrative provisions relating to the classification, packaging and labelling of dangerous substances, C.2. Acute toxicity test Daphnia: Commission of the European Communities; 1992.

Jonczyk E, Gilron G. Acute and chronic toxicity testing with Daphnia sp. In: Blaise C, Férard JF, editors. Small-scale Freshwater Toxicity Testing for freshwater Environments. Smallscale Freshwater Toxicity Investigations, Vol. 1, Toxicity Test Methods. Springer, 2005, pp. 337-93.

Organization for Economic Cooperation and Development. Test No. 202: Daphnia sp. Acute Immobilisation Test, OECD Guidelines for Testing of Chemicals, Section 2: OECD; 2004. $12 \mathrm{p}$.

Persoone G, Baudo R, Cotman M, Blaise C, Thompson KC, Moreira-Santos M, et al. Review on the acute Daphnia magna toxicity test - Evaluation of the sensitivity and the precision of assays performed with organisms from laboratory cultures or hatched from dormant eggs. Knowl Manage Aquat Ecosyst 2009;393:29.

University of Hertfordshire. The Pesticide Properties DataBase (PPDB) developed by the Agriculture \& Environment Research Unit (AERU), University of Hertfordshire, 20062013. Accessed September-October, 2012, and May, 2013, at http://sitem.herts.ac.uk/aeru/ppdb/en/index.htm.

U.S. Environmental Protection Agency. Ecological Effects Test Guidelines. OPPTS 850.1010 Aquatic Invertebrate Acute Toxicity Test, Freshwater Daphnids, Public Draft. Washington, DC: U.S. Environmental Protection Agency, Office of Prevention, Pesticides and Toxic Substances; 1996. EPA 712-C-96-114. 10 p.

U.S. Environmental Protection Agency. Methods for measuring the acute toxicity of effluents and receiving waters to freshwater and marine organisms, Fifth edition. Washington, DC: U.S. Environmental Protection Agency, Office of Water; 2002. EPA 821-R-02-012. 266 p.

U.S. Environmental Protection Agency. ECOTOXicology Database System, Version 4.0. U.S. Environmental Protection Agency, Office of Research and Development and the National Health and Environmental Effects Research Laboratory's Mid-Continent Ecology Division, 2012a. 
U.S. Environmental Protection Agency. Office of Pesticide Programs' aquatic life benchmarks (freshwater). U.S. Environmental Protection Agency, Office of Pesticide Programs. Updated May 30, 2102. Accessed September-October, 2012, at http://www.epa.gov/oppefed1/ecorisk_ders/aquatic_life_benchmark.htm. 